\title{
The impacts of climate change on bank performance: What's the mediating role of natural disasters?
}

\author{
Wan-Li Zhang ${ }^{1} \cdot$ Chun-Ping Chang $^{2}$ (D) Yang Xuan ${ }^{3}$
}

Received: 15 March 2021 / Accepted: 16 November 2021 / Published online: 30 November 2021

(c) The Author(s), under exclusive licence to Springer Science+Business Media, LLC, part of Springer Nature 2021

\begin{abstract}
This research estimates the effect of climate change on bank performance by considering the mediating role of natural disasters via unbalanced panel data from 2005 to 2018 in 127 countries. Moreover, this paper uses forest land, carbon dioxide emissions, and temperature change to measure climate change, takes economic loss and the number of deaths as costs of natural disasters, and utilizes the non-performing loan ratio and the ratio of bank capital to assets as bank performance. The following conclusions are reached according to our empirical evidence. First, forest land has a strong negative effect on the non-performing loan ratio. Second, forest land decreases the economic losses and deaths due to natural disasters, and natural disasters also decrease banks' non-performing loan ratio. We also find that forest land increases the ratio of bank capital to assets through decreasing natural disasters. Third, there is a significant mediating effect of climate change on bank performance via natural disasters in high-income countries, but not in low-income countries. Finally, the decline of forest land and the rise of carbon dioxide emissions both have significantly positive effects on man-made disasters, which increase banks' non-performing loan ratio and decrease the ratio of bank capital to assets. One policy implication is that improving climate change, preventing natural disasters, and promoting financial institutions can help decrease the economic losses of natural disasters and banks.
\end{abstract}

Keywords Climate change $\cdot$ Bank performance $\cdot$ Natural disasters $\cdot$ Mediating effect model $\cdot$ Simultaneous equations

JEL Classification $\mathrm{J} 13 \cdot \mathrm{G} 21 \cdot \mathrm{Q} 54$

Chun-Ping Chang

cpchang@g2.usc.edu.tw

1 School of Public Policy and Administration, Northwestern Polytechnical University, Xi'an, Shaanxi, China

2 Shih Chien University, Kaohsiung, Taiwan

3 School of Humanities, Xidian University, Xi' an, Shaanxi, China 


\section{Introduction}

Climate change has been constantly affecting the environment, production, and life in the world, and the average global temperature in 2019 is 1.1 degrees higher than that of the pre-industrial period. In fact, 2015-2019 was the hottest five years on record, and 2010-2019 was the hottest decade on record. ${ }^{1}$ High temperatures also create excellent conditions for forest fires. Moreover, climate change analysis from the National Aeronautics and Space Administration (NASA) shows that ice in the Arctic is melting at a rate of $13.2 \%$ per year. Xi et al. (2012) point out that forest ecosystems can prevent typhoons and earthquakes. Furthermore, the increase of carbon dioxide emissions, caused by forest fires, vehicles, and industries, also leads to the greenhouse effect, which further raises global temperatures (Lashof and Ahuja 1990; Fu et al. 2020; Chang and Zhang 2020). Changes in forest land, carbon dioxide emissions, and temperature affect glaciers, rainfall, warm and humid airflow, and even atmospheric pressure, which can increase the frequency of earthquakes, droughts, floods, landslides, and storms. High temperature can even accelerate the spread of virus, which may cause epidemic (Chang and Berdiev 2015; Zickfeld et al. 2016; Harmooshi et al. 2020). The changing of atmosphere may affect the absorption of the sunlight and alter the geothermal energy, which result in crustal movement and volcanic eruption.

Natural disasters can cause the collapse of residents' houses and enterprises' factories and threaten human health and lives. Residents and enterprises might then not be able to repay loans, borrow more money from banks, or take out their bank deposits in order to maintain their living standard and production (Adebisi and Matthew, 2015; Amin et al. 2019). Climate change along with forest land, carbon dioxide emissions, and temperature change may exhibit impacts on bank performance through natural disasters (Levy et al. 2016; Cortés and Strahan 2017). Moreover, countries with different income levels suffer from different damage risks due to natural disasters (Kellenberg and Mobarak 2008). This present research argues that climate change may bring about the occurrence of natural disasters, and then natural disasters affect bank performance-namely, natural disasters are the mediating variables between climate change and bank performance. It is important to study the mediating effect of climate change on bank performance through natural disasters and to analyze the different influences by considering income heterogeneity.

Disasters consist of natural disasters, which may be caused by mother nature, and man-made disasters, which are mainly produced by human activities. Man-made disasters include industrial accidents, transport accidents, and miscellaneous accidents according to the description of EM-DAT (international disasters database), which can be divided into fire, explosion, collapse, air, gas leak, chemical spill, oil spill, and so on. Does climate change also affect man-made disasters? The answer is most likely yes. Extreme high temperature may directly cause fires and impair plant equipment and vehicles, which can lead to industrial accidents and transport accidents (Labovská et al. 2014). Heavy rain, snowstorms, and strong wind may lead

\footnotetext{
${ }^{1}$ Source: Statement on the State of the Global Climate Situation in 2019, proposed by World Meteorological Organization.
} 
to electrical short circuits and fires and also increase the operation errors of drivers of vehicles such as cars and trucks as well as pilots of ships, which could result in a gas leak, oil leak, and so on. Hence, climate change has an effect on natural disasters and man-made disasters and is bad for bank performance by leading to property losses for residents and enterprises.

Our first purpose is to study the relationships among climate change, natural disasters, and bank performance. There is already a large amount of research about the influence of climate change on natural disasters (Hirsch and Ryberg, 2012; Khan et al. 2015; Sant'Anna 2018), and the literature has also analyzed the relation between natural disasters and bank performance (Brahmana et al. 2016; Mourouzidou-Damtsa 2019). However, scant studies have looked into how climate change affects bank performance, such as the mediating effect of natural disasters, and that different climate change factors have various impacts on different natural disasters. Therefore, this paper uses total economic losses and deaths to measure the effect of natural disasters, such as droughts, floods, storms, extreme temperatures, epidemics, earthquakes, and landslides. ${ }^{2}$ Furthermore, we employ a mediating effect model to estimate the mechanism of natural disasters with regard to simultaneous equations, three-stage least square method, and panel fixed effect model. Overall, we confirm that there exists a mediating effect of climate change on bank performance through economic losses due to natural disasters. This paper also uses man-made disasters to find the mediating effect of climate on bank performance.

We next shall investigate different types of heterogeneity of climate change on bank performance through natural disasters under different income levels. Because high-income countries have better infrastructure, more skilled labor, and perfect financial institutions, they generally have changed from resource-intensive to technology-intensive industries and have greater focus on environmental protection, services, and residents' living standards. Hence, natural disasters caused by climate change produce fewer deaths and economic losses in high-income countries than in low-income countries. Moreover, perfect financial institutions can also lend money to individuals and enterprises, which means non-performing loans and capital shortage in the short term, but it is still good for development in the long run (Herold et al. 2017; Song et al. 2021). Low-income countries usually have underdeveloped financial systems, economies, infrastructure, and technologies. Moreover, poor technology and resource constraints make them unable to obtain loans to expand scale and innovation. The financial institutions in these low-income countries are also relatively backward and may not be able to provide sufficient loans for individuals and enterprises. Therefore, there may exist different mediating effects of climate change on bank performance via natural disasters in high-income countries, but insignificant effects in low-income countries.

\footnotetext{
2 The data and classification standard of an epidemic come from the EM-DAT database and refer to cholera, malaria, dengue fever, yellow fever, and so on. Epidemics occur mainly due climate change, and a rise in temperature provides a comfortable growth environment for mosquitos, parasites, etc. that may accelerate the spread of an epidemic. Furthermore, climate change is accelerating the melting of glaciers and releasing ancient viruses, which may have a bad influence on humans. Heavy rains and snowstorms also may spread viruses through the flow and drinking of water.
} 
Though the effect of climate change on bank performance is weak, it can lead to deaths and economic losses through natural disasters (Khan et al. 2015; Zickfeld et al. 2016; Dalmagro et al. 2019). When natural disasters hinder the repayment of loans by residents and enterprises, these entities then withdraw their bank deposits for living, production, and reconstruction, which influence non-performing loans and bank capital (Mourouzidou-Damtsa 2019). First, the most obvious feature of climate change is higher temperatures. The global warming caused by greenhouse gases accelerates the melting of glaciers in the north and south poles as well as in high mountains, which then change the sea level and inland river distribution. As temperatures rise, the evaporation of rivers and oceans alters ocean currents which may directly lead to storms, droughts, and floods (Ardhuin et al. 2017). Forest land and grassland also change carbon dioxide emissions, which may lead to greenhouse warming, by producing clean gases via absorption of carbon dioxide. Furthermore, the roots of trees and grasslands stabilize the soil and retain water to prevent desertification and reduce damage from earthquakes and landslides. A dense forest can form a protective wall to reduce wind speed and effectively resist storms and hurricanes in coastal regions (Fernandes et al. 2018). Therefore, climate change can lead to deaths and economic losses through natural disasters.

Second, the shock of a natural disaster on a region is quite obvious. In general, natural disasters, including earthquakes, hurricanes, tsunamis, and volcanic eruptions, bring serious harm to residents and enterprises through deaths, the collapse of houses and factories. The property of humans in affected areas also suffer severe losses, and if an enterprise is on the verge of bankruptcy, then it makes it impossible to repay bank loans (Cole et al. 2019; Chen et al. 2021). Conversely, governments can provide fiscal help to these people and enterprises and require banks to assist them in order to stabilize society and the economy. Therefore, natural disasters have an impact on bank performance (Brei et al. 2019). Although floods, droughts, and epidemics do not necessarily lead to deaths and bankruptcies, they can reduce agricultural and industrial output and make people sick, which also means using their savings to treat any diseases and maintain their livelihood. The profits of enterprises will also decrease, potentially resulting in the inability to repay loans in the short term. Overall, there exists an indirect influence of climate change on bank performance through the deaths and economic losses of natural disasters.

The contribution of this paper is as follows. First, we analyze the impacts of climate change on bank performance by using unbalanced panel data of 127 countries from 2005 to 2018. We decompose climate change into three aspects-namely forest land, carbon dioxide emissions, and temperature change - and use the bank nonperforming loan ratio and the ratio of capital to assets to measure bank performance. Second, we employ the mediating model, considering the three-stage least square method, to test the indirect effect of climate change on bank performance via natural disasters, which refer to total economic losses from natural disasters. Finally, to overcome heterogeneous problems and provide robust evidence, the sample is divided into high- and low-income countries, because high-income countries with better financial institutions can lend money to residents and enterprises more convenient, while it is almost impossible in low-income countries. There are different effects of climate change on bank performance through natural disasters in countries 
with different income levels. Therefore, we divide the sample into high-income countries and low-income countries and conclude that the effect of climate change on bank performance via natural disasters in the former is significant, but insignificant in the latter.

The paper proceeds as follows. Section 2 summarizes the previous literature review and proposes the hypotheses. Section 3 presents the benchmark model based on the mediating model and the choice of variables. Section 4 lays out the estimation for the effect of climate change on bank performance through natural disasters and man-made disasters, discusses the results, tests the hypothesis by considering income heterogeneity, and contains robustness checks. Finally, Sect. 5 concludes and puts forward policy suggestions.

\section{Literature review and hypothesis}

\subsection{Literature review}

(1) The influence of climate change on natural disasters.

It is obvious that the climate of the world is fluctuating. Temperatures are increasing, and heavy precipitation and extreme temperatures are already happening with greater occurrence (Knowles et al. 2006). Many researchers are highly convinced that these phenomena can be linked to carbon dioxide emissions and other greenhouse gases, which come from the production of enterprises human living (Montzka et al. 2011; Cox et al. 2013; Chang and Berdiev 2013). Climate change consists of weather, climate, greenhouse gases, oceans, ice and snow, temperatures, carbon dioxide, and forest land. ${ }^{3}$ And climate change also poses many threats to lives and production around the world, including a greater risk of extreme temperatures, floods, droughts, heavy tsunamis, and storms as well as increasing risk of asthma attacks and the spread of certain diseases carried by ticks and mosquitoes (Diaz 2006; Ardhuin et al. 2017).

This research thus analyzes the influences of temperature change, carbon dioxide, and forest land on bank performance. First, forests can absorb carbon dioxide emissions from humans and production, which help decrease greenhouse gases in the atmosphere. Moreover, forests can stabilize soil, prevent floods, and provide protective walls for regions against sandstorms, tsunamis, and hurricanes (Modarres et al. 2016). Second, as the major part of greenhouse gases, carbon dioxide changes the pressure and temperature of the atmosphere and can also cause extreme temperatures. The melting of glaciers in the north and south poles and high mountains also changes the flow and sea level of rivers and oceans, which lead to droughts and floods (Hirsch and Ryberg, 2012; Ardhuin et al. 2017). The storage of heat and energy in the atmosphere, caused by carbon dioxide, can change the surface temperature, leading to crustal movements and earthquakes. Finally, temperature, as the most sensitive factor of climate change, also affects droughts, floods, storms, and

\footnotetext{
${ }^{3}$ Source: Climate Change Indicators in the United States in 2016, proposed by United States Environmental Protection Agency.
} 
epidemics (Levy et al. 2016). High temperatures accelerates evaporation and ocean currents, changing rainfall and drought. Extreme temperature also affects human health and deaths. In conclusion, humans suffer from natural disasters caused by climate change, such as temperature change, carbon dioxide, and forest land.

(2) The influence of natural disasters on bank performance.

The occurrence of natural disasters has an obvious impact on regional economy, society, and human beings (Wen et al. 2021; Loayza et al. 2012). First, natural disasters have the most direct impact on agricultural production, because agriculture depends on natural factors such as land use and weather (Keerthiratne and Tol 2018). There is a negative effect on the growth of crops when the temperature is too high or too low. Floods and storms also exert devastating damage to crops (Narayan 2003). Natural disasters, such as earthquakes, hurricanes, and volcanoes, also cause damage to farms and factory workshops, which may reduce the supply of raw materials, destroy production equipment, and cause turnover and death of workers (Hassan 2010). Agriculture and manufacturing firms might be unable to repay their bank debts, and governments may force banks to finance damaged enterprises to help with economic recovery, which will increase bank risks (Cole et al. 2019).

Second, natural disasters also have a direct impact on human beings. People mainly rely on planting crops to maintain their daily life needs. Urban and suburban residents can get a stable salary by working at an enterprise, which lets them buy other goods, conduct their own investments, and even enjoy life (Yang et al. 2018). However, residents can lose jobs, suffer famine, and suddenly have no permanent residence, and even their health and life will be threatened when natural disasters come (Wang and Taylor 2018). In addition, people may reduce their savings and not be able to repay loans from banks, thus increasing non-performing loans (Pennacchi 2006; Amin et al. 2019).

Third, natural disasters force enterprises and residents to hold large amounts of cash and reduce the capital of banks (Mourouzidou-Damtsa 2019). In addition, cash might also be burned and destroyed when buildings are destroyed via natural disasters such as earthquakes, volcanos, etc. (Shirai and Sugandi 2019). The bank of disaster suffered regions may also face catastrophic damage and reduce the capital of banks. All these phenomena can lower the cash flow of the whole economy and reduce the ratio of bank capital to assets, which has a significant effect on bank performance. In short, natural disasters influence bank performance by destroying the houses and factories of residents and enterprises and by hindering the operations of agriculture and manufacturing.

(3) The influence of man-made disasters.

Climate change can also affect man-made disasters, including industrial accidents, transport accidents, and miscellaneous accidents (Labovská et al. 2014; Li et al. 2019). This paper also analyzes the influences of climate change on man-made disasters from three aspects: temperature change, carbon dioxide, and forest land. First, Islam et al. (2019) pointed out that climate change is causing a big rise in temperatures and the frequency of sandstorms and is altering rainfall patterns in Saudi Arabia as in other parts of the world. They concluded that temperature, rainfall, sandstorms, and numbers of vehicles are responsible for increasing road traffic accidents. Barrimah et al. (2012) also considered that climate change leads to traffic accidents, 
which can threaten the health of humans. Forest land is able to help inhibit sandstorms, strong winds, and other inclement weather (Yang et al. 2019). Therefore, forest land affects man-made disasters directly. Second, Huang et al. (2019) noted that the flammability and explosion characteristics of natural gas and air mixtures at high pressure and high temperature are great concerns of industries. Extreme high temperature can cause flammable explosions and industrial fires. Hence, temperature change also has a strong influence on man-made disasters. Finally, the increase of carbon dioxide emissions changes the atmospheric structure, resulting in extreme climate in recent years. The most direct impact of carbon dioxide is raising global temperatures, which can trigger more disasters such as heavy rains, blizzards, and hurricanes (Belingardi et al. 2010). Heavy rains and snowstorms can directly affect electrical short circuiting, which causes fires and explosions. Heavy rains and snowstorms also cause roads to become slippery and icy, increasing driving difficulty and traffic accidents (Lee et al. 2015). Overall, the above literature and studies conclude that climate change affects the costs from man-made disasters.

Do man-made disasters impact bank performance? Thiagarajan (2018) revealed that man-made disasters, similar to natural disasters, also increase the ratios of nonperforming loans to total loans and loan loss reserves to total loan of banks. Residents and enterprises, when faced with man-made disasters, can lose property and money, and even their lives and health can even be threatened. When this happens, enterprises cannot produce and obtain profits, and residents need to spend money for medical treatment. All these events can lead to a failure to repay bank loans, which is bad for the development of banks. Zhao et al. (2021) found that natural catastrophes and man-made disasters have distinct impacts on the insurance industry, because they need to pay out a lot of insurance coverage. In addition, disasters, both natural and man-made, hugely impact the victims themselves and financial institutions (Wen et al. 2020).

\subsection{Hypothesis}

The analysis above shows that climate change, including forest land, carbon dioxide emissions, and temperature change, leads to a variety of natural disasters. Some disasters can do devastating damage to cities and residents, while some can cause damage to agriculture and industry and affect the profits of enterprises (Guerreiro et al. 2018). In short, natural disasters bring negative effects to people and enterprises. First, residents' lives and health are threatened, forcing them to use a lot of money to maintain their lives and treat any diseases, and they may decrease their deposits and increase loans from bank. Second, natural disasters can impact cities, including the houses of residents, who then take their deposits out of banks and increase loans to build homes and make sure they have a place to live (Baryshnikova and Pham 2019). Third, the factories of enterprises can be destroyed by natural disasters, resulting in lower profit. The enterprises may not have enough capital to expand their scale, research and development, and even run normal production. Thus, they may stop investing and may not be able to repay their bank loans (Cole et al. 2019). 
Climate change thus affects natural disasters, which influence banks' non-performing loan ratio.

Hypothesis 1: Climate change has a mediating effect on banks' non-performing loan ratio -namely, the mediating effect of natural disasters is significantly negative for forest land, and there exists a positive indirect effect from carbon dioxide.

Since the capital of banks is also affected through death and sickness of humans, as well as the economic losses of enterprises and residents caused by climate change, we analyze the effect of natural disasters on bank's ratio of capital to assets. Noth and Schüwer (2017) indicated that weather-related natural disasters decrease Z-scores, return on assets, and bank equity ratios and increase the non-performing loan ratio, foreclosure ratio, and default risk. First, financial institutions, such as banks, securities firms, and insurance companies, have more outlets, and natural disasters have a negative impact on them. For example, the collapses of banks may lead to cash loss (Samantha 2018; Albuquerque and Rajhi 2019). The network system of banks can also be destroyed, which leads to capital loss. Second, the economic losses of residents and enterprises, deaths and sicknesses, and collapsed houses and factories all increase the demand for cash by people and enterprises. They thus withdraw their deposits, which reduce the capital of banks (Cole et al. 2019). Finally, natural disasters lead to the loss of corporate profits and the constraints of technology, which affects the capital of banks. Hence, climate change has an influence on natural disasters, which may decrease bank capital.

Hypothesis 2: Climate change has an indirect effect on the ratio of bank capital to assets. The mediating effect of forest land through natural disasters is positive, while it is negative for carbon dioxide emissions and temperature change.

Sommer (2019) pointed out that forestry rents, GDP per capita, and economic growth are all related to forest loss. Therefore, forest loss is different in low-, middle-, and high-income areas. Herold et al. (2017) also indicated that despite greenhouse gas emissions of low-income countries contributing the least to climate change, they are already facing greater increases in the occurrence of extreme temperature. In short, climate change in countries' different characteristics, such as income heterogeneity, GDP heterogeneity, and labor heterogeneity. First, the wage of people of low-income countries is meager, enterprises are mainly engaged in agriculture and low-end production, showing that there is no surplus capital for deposits in banks, and people are not willing to borrow money from banks to innovate. Moreover, financial institutions in low-income countries are underdeveloped and may not be willing to provide loans to enterprises and residents. Hence, this has an insignificant effect on bank performance. Second, people in developed countries or high-income countries have high living standards and wages, and enterprises are mainly capital- and technology-intensive. In addition, residents have free money to deposit in banks, have the energy and knowledge to invest, and even borrow money to invest. Enterprises also want loans from banks to innovate and for development and research. When enterprises close down due 
to natural disasters, the lives and properties of residents are damaged, which will then affect investment profits and loan recovery of banks-namely bank performance (Noy 2009).

Hypothesis 3: The mediating effects of climate change on bank performance exhibit heterogeneity between low- and high-income countries.

Nezamodini et al. (2015) proposed that flammability and reactivity of materials, high temperature, operation pressure, and volatility and evaporability of liquids may result in fires and explosions especially for industries with high frequency use of hydrocarbons. Cheng et al. (2018) and Li et al. (2019) pointed out that heavy fog, haze, and sandstorms, leading to low sight visibility, are the main reasons for transport accidents. Therefore, climate change, such as extreme temperatures, fog, sandstorms, heavy rains, windstorms, and so on, will affect the cost of industrial accidents, transport accidents, and miscellaneous accidents, which we refer to as man-made disasters. Furthermore, man-made disasters have a bad influence on the property and safety of residents and enterprises, resulting in their inability to repay debts and thus affecting bank performance.

First, inflammables increase the probability of explosions and fires when encountering extreme high temperature. Strong winds, rainstorms, and blizzards may stir up inflammables, destroy buildings, and even create electrical short circuits and industrial accidents. Moreover, the above analysis shows that heavy fog, haze, and sandstorms also hinder sight visibility, which can result in transport accidents. Oil tankers may see increased operational errors that lead to oil spills when extreme climate change occurs. In addition, climate change also affects man-made disasters like natural disasters.

Second, suffering from man-made disasters, residents could lose their property and become sick, forcing them to spend money to get better and/or being unable to repay banks' loans. Man-made disasters also damage machines and equipment, which make enterprises lack the capacity for full production and thus temporarily or permanently see their profit fall. They may even be unable to repay bank loans. Therefore, manmade disasters have negative impacts on banks' loans, debts, and capital, which will increase banks' non-performing loan ratio and decrease the ratio of bank capital to assets.

Hypothesis 4: The mediating effect of forest land through man-made disasters is positive, while it is negative for carbon dioxide emissions and temperature change.

\section{Benchmark model and variables}

\subsection{Mediating effects analysis method}

The above literature review shows that there is no direct impact of climate change on bank performance, but climate change has a mediating effect on bank performance via natural disasters. The mediating effect reveals that the relation between an 
independent variable $(X)$ and a dependent variable $(Y)$ is transmitted through a third variable $(M)$, referred to as the "mediator". We can analyze the mediator's effect (direct and indirect effects) and verify how climate change influences bank performance via natural disasters by considering the mediating effect model. The mediating effect model is first used in social psychology with regard to time series data or cross-sectional data (Tofighi and MacKinnon 2011). Cao et al. (2017) improved the mediating effect model by considering panel data, which consists of three models. Our study also follows this method, as shown in Eqs. (1) to (3).

$$
\begin{gathered}
Y_{i t}=C_{1}+\alpha \times X_{i t}+\varepsilon_{i t} \\
M_{i t}=C_{2}+\beta \times X_{i t}+\zeta_{i t} \\
Y_{i t}=C_{3}+\gamma \times M_{i t}+\chi \times X_{i t}+\xi_{i t}
\end{gathered}
$$

We note that coefficient $\alpha$ is the total impact of independent variable $X$ on dependent variable $Y$. Coefficient $\beta$ represents the influence of independent variable $X$ on mediating variable $M$. Coefficients $\chi$ and $\gamma$ denote the effect of independent variable $X$ and mediating variable $M$ on dependent variable $Y$, respectively. Moreover, $\varepsilon_{i t}, \zeta_{i t}$, and $\xi_{i t}$ are error terms. Variables $i$ and $t$ indicate the individual and year. Parameters $C_{1}, C_{2}$, and $C_{3}$ are constant terms. ${ }^{4}$ We get the following result by bringing Eq. (2) into Eq. (3).

$$
\begin{gathered}
Y_{i t}=C_{3}+\gamma \times C_{2}+\gamma \times \beta \times X_{i t}+\chi \times X_{i t}+\gamma \times \zeta_{i t}+\xi_{i t} \\
\alpha^{\prime}=\gamma \times \beta+\chi
\end{gathered}
$$

Coefficient $\alpha^{\prime}$ is the sum of indirect effect $(\gamma \times \beta)$ and direct effect $(\chi)$, which is almost equal to coefficient $\alpha$. The existing literature reveals that Eqs. (2) and (3) are mainly estimated with regard to the method of simultaneous equations (Sarkis et al. 2010). However, this method is not adapted to panel data, and we need to improve Eqs. (1) to (3) as follows.

$$
\begin{gathered}
Y_{i t}=C_{1}+\alpha \times X_{i t}+Z_{i}+\varepsilon_{i t} \\
M_{i t}=C_{2}+\beta \times X_{i t}+V_{i}+\zeta_{i t} \\
Y_{i t}=C_{3}+\gamma \times M_{i t}+\chi \times X_{i t}+U_{i}+\xi_{i t}
\end{gathered}
$$

Variables $Z_{i}, V_{i}$, and $U_{i}$ are the average of dependent variables of individual $i$. How does one verify the existence of a mediating effect? The traditional measurement

\footnotetext{
${ }^{4}$ Parameters $C_{1}, C_{2}$, and $C_{3}$ aim to ensure that the mean values of the error terms are 0 . Generally speaking, the mean value of the dependent variable is not equal to 0 . This paper introduces constant terms to ensure unbiased of results. Furthermore, the dependent variables in Eqs. (1) to (3) are different, which lead to differences in constant terms.
} 
is stepwise multiple regression analysis (Okubo et al. 2017). Wang and Xiong (2021) indicated that the mediating effect requires three steps to verify the stepwise regression method. First, independent variable $X$ must have a significant impact on dependent variable $Y$. Second, we need to verify parameter $\beta$ in Eq. (6) when the first step is right. Third, mediating variable $M$ affects dependent variable $Y$ strongly. In addition, the mediating effect exists when the above three steps are all significant. However, Eqs. (6) and (7) are generally established at the same time, which means that independent variable $X$ affects mediating variable $M$, while mediating variable $M$ also has an impact on dependent variable $X$. Therefore, it is necessary to consider simultaneous equations analysis instead of stepwise multiple regression analysis. Moreover, there may also exist a situation that independent variable $X$ has no direct influence on dependent variable $Y$, but will affect dependent variable $Y$ through mediating variable $M$ indirectly. Furthermore, does the mediation effect exist if at least one of the parameters $\gamma$ and $\beta$ is insignificant? Hence, we cannot test the significance of the coefficients $\gamma$ and $\beta$, because the mediating effect is the product of these two coefficients. This paper thus uses the Sobel test to verify the significance of the mediating effect $\gamma \times \beta$ (Panagiotis and Victoria 2016; Zheng et al. 2019).

$$
\text { Sobel test }=\hat{\gamma} \hat{\beta} / \sqrt{\hat{\gamma}^{2} S_{\beta}^{2}+\hat{\beta}^{2} S_{\gamma}^{2}}
$$

Here, parameters $S_{\gamma}^{2}$ and $S_{\beta}^{2}$ are the standard errors of the coefficients $\beta$ and $\gamma$. The Sobel test follows the Z-statistic based on the normal distribution.

\subsection{Empirical model}

According to the above analysis, we set up the mediating model by considering climate change, natural disasters, and bank performance as follows.

$$
\begin{aligned}
\text { bank performance }_{i t}= & C_{1}+\alpha \times c \lim \text { ate change }_{i t}+\lambda_{1} \times D_{i t}^{1}+Z_{i}+\varepsilon_{i t} \\
\text { natural disasters }_{i t}= & C_{2}+\beta \times c \lim \text { ate change } \\
& \\
\text { bank performance }_{i t}= & C_{3}+\gamma \times \lambda_{2} \times D_{i t}^{2}+V_{i}+\zeta_{i t} \\
& +\lambda_{3} \times D_{i t}^{3}+U_{i}+\xi_{i t}
\end{aligned}
$$

Here, parameters $i$ and $t$ denote region and year, respectively. This paper uses the non-performing loan ratio $\left(B A D L_{i t}\right)$ and the ratio of capital to assets $\left(A S S R_{i t}\right)$ to measure bank performance. Forest land $\left(F O R_{i t}\right)$, carbon dioxide emissions $\left(C A R B_{i t}\right)$, and temperature change $\left(T E M P_{i t}\right)$ represent climate change. We also use the total affected economic loss from droughts, floods, storms, extreme temperatures, epidemics, earthquakes, and landslides to measure the effect of natural disasters $\left(D I S A_{i t}\right)$. The control variables $D_{i t}^{1}, D_{i t}^{2}$, and $D_{i t}^{3}$ correspond to different dependent variables. 


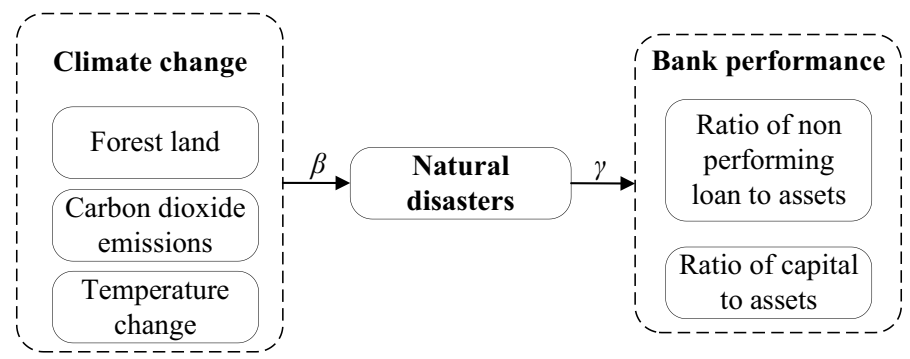

Fig. 1 The mechanism of natural disasters from climate change to bank performance. Note: The parameters of $\gamma$ and $\beta$ are the coefficients of Eq. (9) to (11)

According to the test of the mediating effect, if the coefficient $\alpha$ is significant, then climate change has a total effect on bank performance. The coefficient $\chi$ shows the direct impact of climate change on bank performance, while it is significant. The Sobel test, measured with regard to Eqs. (8), (10), and (11), is significant. There is a mediating or indirect influence of climate change on bank performance via natural disasters. It is noted that there may be no mediating effect, although the coefficients $\gamma$ and $\beta$ are both significant. Figure 1 shows the mechanism of natural disasters from climate change to bank performance.

\subsection{Data and variables}

Annual data on bank performance and control variables for the period 2005-2018 come from the World Bank database. ${ }^{5}$ Relevant data of natural disasters are obtained from EMDAT (international disasters database). Forest land, carbon dioxide emissions, and temperature change data are collected from FAO (database of the Food and Agricultural Organization), and the databases of World Bank and NASA-GISS (National Aeronautics and Space Administration Goddard Institute for Space Studies). There exist 127 countries, and the data are unbalanced panel data, since the data of some countries and years are missing. In addition, there are 11 low-income countries, 29 medium low-income countries, 42 medium high-income countries, and 45 high-income countries.

\footnotetext{
5 Although the data of natural disasters span 1960 to 2019, the data of climate change and other control variables do not due to the limitation of data source. Therefore, the data in this paper run from 2005 to 2018.
} 
Dependent variable (Bank performance). ${ }^{6}$

a. $B A D L$.

This paper uses the non-performing loan ratio $(B A D L)$ to measure bank performance (Jiménez et al. 2013; Us 2017). Brahmana et al. (2016) used the event study approach and indicated that the Aceh tsunami had a significant effect on the nonperforming loan ratio of local banks in Indonesia. In addition, enterprises and residents face a huge impact when natural disasters occur. Enterprises' factories and residents' houses may collapse during earthquakes, storms, and floods. They then may be unable to pay back bank loans, which results in increasing non-performing loans in banks. Therefore, this paper uses the non-performing loan ratio to measure bank performance.

b. ASSR.

The non-performing loan ratio is closely related to the ratio of capital to assets $(A S S R)$. The above analysis shows that natural disasters not only affect the production of enterprises and the livelihood of humans, which leads them to be unable to repay debts, but also reduce cash on hand, collateral, etc. These phenomena reduce a bank's physical and intangible capital and decreases the capital-asset ratio. This paper uses the ratio of capital to assets to represent bank performance (Klomp 2014; Mourouzidou-Damtsa, 2019).

Independent variable (Climate change).

a. FOR.

Khan et al. (2015) indicated that the decrease of forest land has a significant influence on natural disasters. Forests can reduce $\mathrm{CO} 2$ emissions through their own recycling system and make the land more solid, which can help prevent the negative aftermath of rainstorms and sandstorms. Moreover, the increase of concentrations of heat-trapping greenhouse gases in the Earth's atmosphere can affect atmospheric pressure and influence temperature, which may cause earthquakes and landslides (Xi et al. 2012; Khan et al. 2015). The reduction of forest areas accelerates carbon dioxide emissions and other greenhouse gases into the atmosphere. It is obvious that there exists a negative impact of forest land on natural disasters. Therefore, we use the ratio of forest land to national area $(F O R)$ to refer to the change and influence of forests, obtaining the data from FAO (database of the Food and Agricultural Organization).

b. $C A R B$.

Carbon dioxide emissions make up the main reason for the greenhouse effect (Clough and Iacono 1995). The rise in global temperatures may cause many natural disasters. Hirsch and Ryberg (2012) pointed out that carbon dioxide leads to glaciers melting and the rise of sea levels, which change the flow of air via atmospheric pressure. In response, average temperatures at the Earth's surface are increasing and

\footnotetext{
${ }_{6}$ Insurance companies are also affected by natural disasters. Those insured enterprises and residents, suffering from natural disasters, will obtain compensation through insurance companies, which result in the losses of assets for the insurance companies. Moreover, the suffering enterprises also experience a negative impact on their own stock prices and related sector firms. This paper only analyzes the relationships among climate change, natural disasters, and bank performance, and the study of insurance companies or the stock market will be the main focus of the authors' future research.
} 
are expected to continue rising. Because climate change can shift the wind patterns and ocean currents that drive the world's climate system, some areas are warming more than others, and some have experienced cooling. In addition, the temperature rise also promotes the spread of viruses, such as COVID-19 (coronavirus disease) in 2019 (Chang et al. 2021; Long et al. 2021; Wang et al. 2021b). Moreover, the number of extreme weather events is rising, caused by carbon dioxide emissions. This paper collects the ratio of carbon dioxide emissions to national area $(C A R B)$ of different countries to study how they affect bank performance through natural disasters, which come from the World Bank database.

c. TEMP.

Temperature is the most direct factor of climate change (Kenisarin 2010). Warmer temperatures are one of the most direct signs that the climate is changing. The global average surface temperature has risen at an average rate of $0.15^{\circ} \mathrm{F}$ per decade since $1901 .^{7}$ Unusually hot or cold temperatures can result in prolonged extreme weather events like summer heatwaves or winter cold spells (Zickfeld et al. 2016). Heatwaves can lead to illness and death, particularly among older adults, young children, and other populations of concern. In addition, a large change in temperature can cause heavy precipitation, tropical cyclone activity, river flooding, and drought. Therefore, we use temperature change (TEMP) to analyze the effect of climate change on bank risk. We get the data from NASA-GISS (National Aeronautics and Space Administration Goddard Institute for Space Studies).

Mediating variables (Natural disasters).

According to the above analysis, climate change affects different kinds of natural disasters. Therefore, we use the influence of natural disasters (DISA) - namely economic losses - to analyze the mediating effect of climate change on bank performance through natural disasters (Liu et al. 2020). We calculate the sum of economic losses of droughts, floods, storms, extreme temperatures, epidemics, earthquakes, and landslides of each country, because these natural disasters are most relevant to climate change. This paper also uses natural disasters' deaths to verify the robustness test. The data of natural disasters come from EM-DAT (international disasters database), and the indicator can directly reflect the influence and severity of natural disasters (Harrington and Otto, 2020).

Control variables.

This paper also uses the following variables to control the effect of climate change on natural disasters and the impact of natural disasters and climate change on bank performance. First, we use population per unit area (PEON) to measure population density (Marin and Modica, 2017; Wang et al. 2021a). Most likely, many people and economic losses would be involved in natural disasters in high population density regions. Moreover, high population density means that a large number of people will go to banks to deal with deposits and loans, which will affect bank performance. Second, GDP per capita $(G D P)$ reflects the economy of a country (Chen et al. 2019; Lima and Barbosa, 2019). Lee et al. (2017) revealed that people

\footnotetext{
7 Source: Climate Change Indicators in the United States in 2016, proposed by United States Environmental Protection Agency.
} 


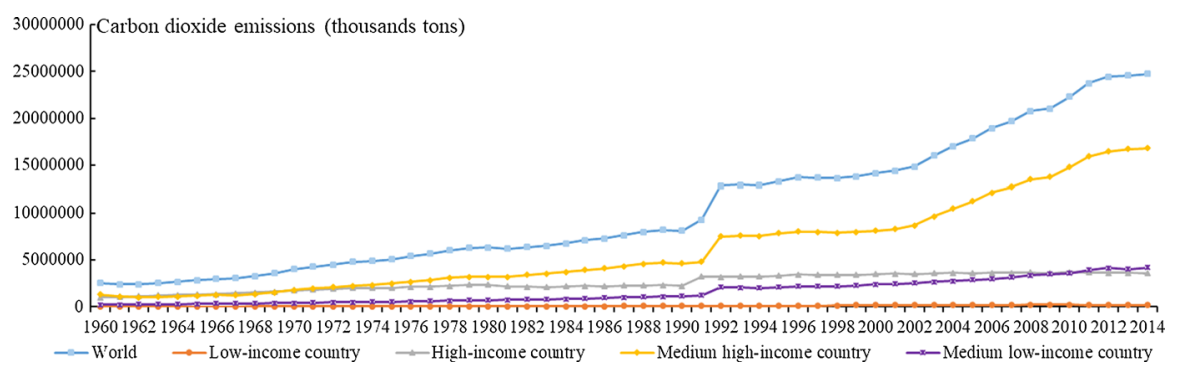

Fig. 2 Carbon dioxide emissions from 1960 to 2014. Note: The data and the classification of countries all come from the World Bank database

have more income and a better life when the country has a higher GDP per capita. In addition, this also means the region has good infrastructure, and high-quality factories and buildings (Feng et al. 2021b; Zheng et al. 2021), which reduce the impact of natural disasters. Residents and enterprises will have closer contact with banks when they have high income and experience good development. For example, people are willing to invest in banks, and enterprises want to borrow from banks for production and innovation, which affect bank performance. Third, Brueckner and Lederman (2015) considered that international trading borrowers are less likely to default on bank loans. It is easier for banks to provide loans and financing to enterprises when international openness is higher. However, trade has no direct impact on natural disasters. Therefore, this paper uses the ratio of trade over GDP (TRADE). Fourth, Boateng et al. (2015) pointed out that inflation appears to have a negative effect on bank performance, such as non-performing loans, capital adequacy ratio, etc. People reduce investment and increase consumption if inflation is too high, which impacts banks. Inflation does not affect natural disasters, because this is mainly caused by human activities and climate and environmental changes. The inflation of each country (INFL) is used to control the influence of climate change on bank performance (Gilchrist et al. 2017). Finally, the interest rate (RATE) is an important measurement for the government to adjust the economy (Yang et al. 2021). Residents typically deposit their capital in banks, and the loan rate of enterprises and individuals will increase when the interest rate is high (Lopez et al. 2020). The interest rate directly affects the performance of banks, but has no effect on natural disasters. The above indicators all come from the World Bank database.

\subsection{Data description}

The data of some variables are missing in terms of year and country, because of availability. For example, the data for the non-performing loan ratio started in 2005. In addition, carbon dioxide emissions are available only until 2014 from the World Bank database and other databases, such as NOAA (National Oceanic and Atmospheric Administration). The data in our paper are unbalanced panel data. Therefore, we delete the missing values of the dependent and independent variables and keep the value of zero of mediating variables. This paper first analyzes the dynamic 


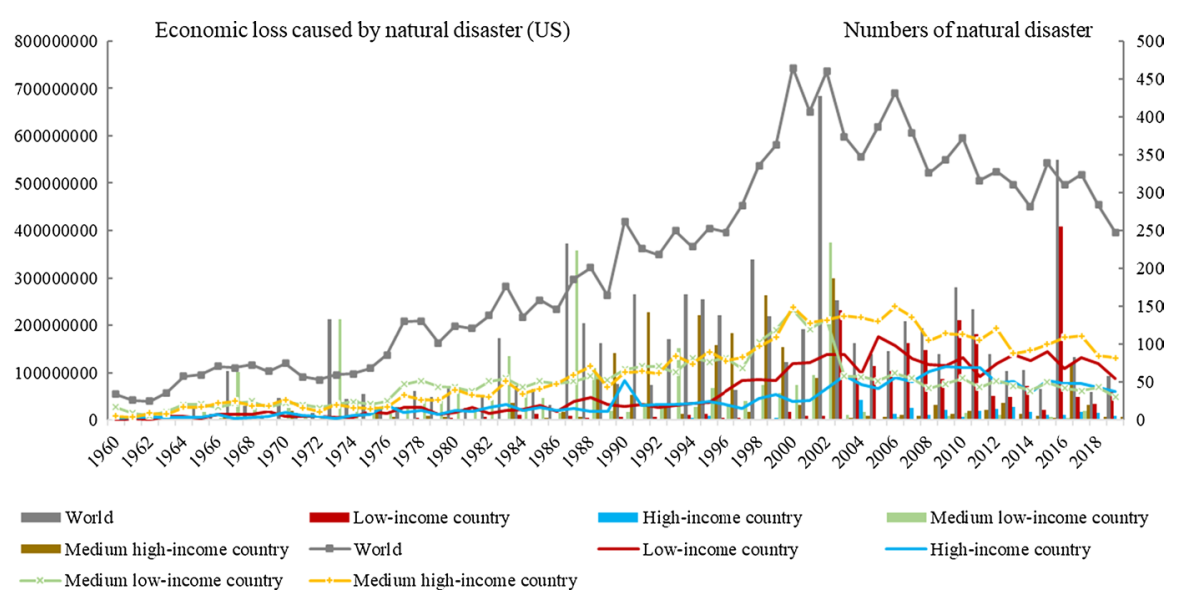

Fig. 3 Economic losses and the number of different natural disasters from 1960 to 2019. Notes: The data come from EMDAT (international disasters database). The classification of countries comes from the World Bank database. The main vertical axis refers to economic losses of natural disasters. The vertical axis refers to numbers of natural disaster. Natural disasters consist of droughts, floods, storms, extreme temperatures, epidemics, earthquakes, and landslides

change of carbon dioxide emissions and the economic losses from different natural disasters. The data summary of this paper is displayed, such as observation, mean, standard deviation, maximum, minimum, and median.

Figure 2 plots the variables for carbon dioxide in different countries from 1960 to 2014 , revealing that most regions exhibit an increase of carbon dioxide emission. First, global carbon dioxide emissions hit 24 trillion tons, which increased by $973 \%$ compared to 1960. Although the amount of carbon dioxide emission for low-income countries is low, it also rose from 15 billion tons in 1960 to 191 billion tons in 2014, or an increase of $1,202 \%$. Medium high-income countries have the highest carbon dioxide emissions, rising from 1 trillion tons in 1960 to 16 trillion thousand tons, for a growth rate of $1,196 \%$. However, high-income countries have the smallest increasing rate at $350 \%$, although they have the best developed economies. These all show that carbon dioxide emissions rose from 1960 to 2014 and will rise in the future.

Figure 3 reveals the trend of economic losses and numbers of natural disasters in different countries by considering income from 1960 to 2019 . We find that natural disasters fluctuate greater than carbon dioxide emissions. The number of natural disasters in the world increased from 34 in 1960 to 248 in 2019 for a growth rate of $741 \%$. The year with the most frequent disasters is 2000 at 465 . Economic loss of the world was US\$92 billion in 2019, which increased 3,200\% from 1960. The worst year was 2002 at US\$684 billion. It is obvious that the number of natural disasters in different types of countries shows an increasing trend, with low-income, medium low-income, medium high-income, and high-income countries rising by $2,700 \%, 182 \%, 1,640 \%$, and $1,900 \%$, respectively. In addition, we find that the economic losses of medium low-income and medium high-income countries accounted for the majority of the world's losses from 1960 to 2003. However, global economic losses were mainly composed of low-income countries after 2003. The economic 


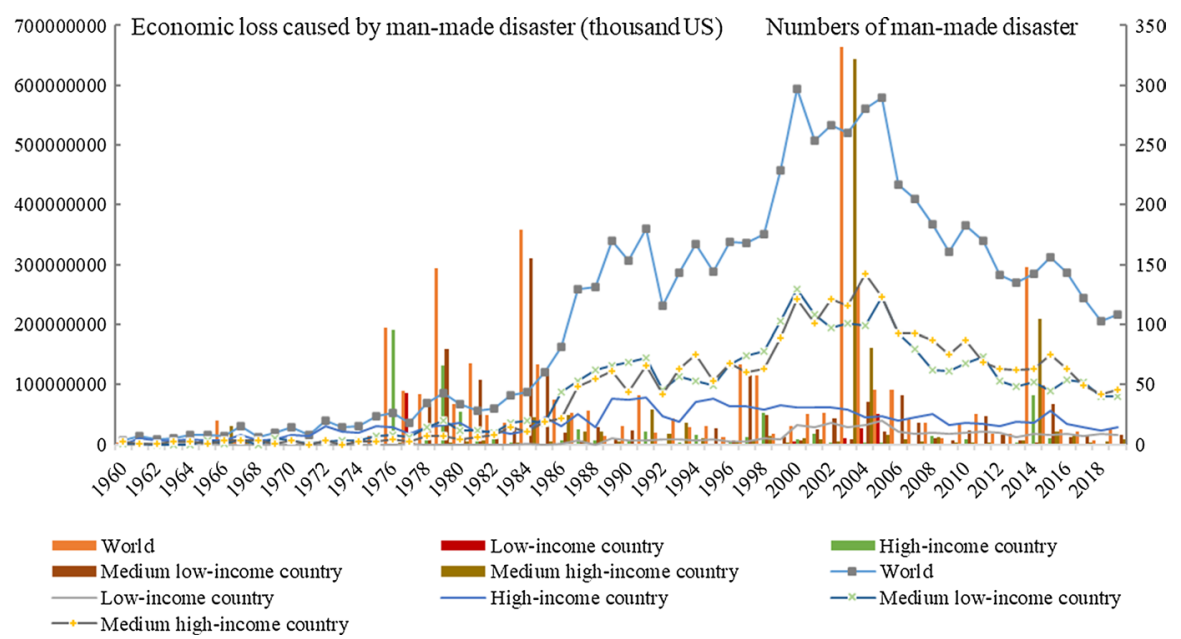

Fig. 4 Economic losses and the number of different man-made disasters from 1960 to 2019. Notes: The data come from EMDAT (international disasters database). The classification of countries comes from the World Bank database. The main vertical axis refers to economic losses of man-made disasters. The vertical axis refers to the numbers of man-made disasters. Man-made disasters consist of industrial accidents, transport accidents, and miscellaneous accidents

losses of the low-income countries were below US $\$ 100$ billion until 2003, whereas this value for high-income countries is always less than US\$50 billion. It shows that the number and economic losses of natural disasters have an increasing trend, but the increase rates, the frequency, and total economic losses vary greatly in different types of countries.

Figure 4 also exhibits the tendency of economic losses and numbers of man-made disasters from 1960 to 2019. Man-made disasters, including industrial accidents, transport accidents, and miscellaneous accidents, are different from natural disasters that cover droughts, floods, storms, extreme temperatures, epidemics, earthquakes, and landslides. Man-made disasters are directly caused by human's daily life activities, factory production, and transportation. However, natural disasters are directly caused by mother nature. The data of man-made disasters come from EM-DAT (international disasters database). We see that the number of man-made disasters in the world rose from 3 in 1960 to 297 in 2000, but then the number of man-made disasters fell to 108 in 2019. Economic losses in the world increased from US\$2.2 billion in 1960 to US\$26 billion in 2019 for a growth rate of $1182 \%$ in nearly 60 years. The worst year was 2003 at US\$663 billion. Moreover, we find that the number of man-made disasters in different types of countries shows an increasing trend except for the years from 2000 to 2006, with the numbers in low-income, medium lowincome, medium high-income, and high-income countries rising by $758 \%, 3,371 \%$, $190 \%$, and $583 \%$, respectively. It is obvious that the economic losses in medium low-income and high-income countries accounted for the majority of the world's losses from 1960 to 2002 . However, after 2003 global economic losses have mainly come from medium low-income and medium high-income economies. In addition, the growth rates in the number or amount of economic losses of man-made disasters 
Table 1 Descriptive analysis of all variables

\begin{tabular}{lllrrlrr}
\hline ID & Variable & Observations & Mean & SD & Min & Median & Max \\
\hline 1 & BADL & 1363 & 6.566 & 6.960 & 0.082 & 4.069 & 59.757 \\
2 & ASSR & 1363 & 10.341 & 3.877 & 1.490 & 10.024 & 24.849 \\
3 & DISA & 1820 & 0.382 & 15.357 & 0 & 0.001 & 654.837 \\
4 & FOR & 1651 & 0.031 & 0.021 & 0.001 & 0.031 & 0.088 \\
5 & CARB & 1300 & 1.131 & 5.523 & 0.001 & 0.186 & 78.779 \\
6 & TEMP & 1690 & 0.796 & 0.611 & -0.320 & 0.780 & 2.944 \\
7 & PEON & 1820 & 0.020 & 0.065 & 0.001 & 0.008 & 0.784 \\
8 & GDP & 1820 & 1.498 & 1.956 & 0 & 0.673 & 11.197 \\
9 & TRADE & 1820 & 89.778 & 57.253 & 0 & 80.471 & 437.327 \\
10 & INFL & 1820 & 5.473 & 7.828 & -29.691 & 3.650 & 100.627 \\
11 & RATE & 1820 & 4.362 & 7.322 & -33.597 & 2.677 & 54.678 \\
\hline
\end{tabular}

The table shows the observations, mean, SD (standard deviation), minimum value, median value, and maximum value of all variables

Table 2 Panel unit root test

\begin{tabular}{lcl}
\hline Variable & Fisher-test & P-value \\
\hline BADL & 14.986 & 0.00 \\
$A S S R$ & 24.538 & 0.00 \\
$D I S A$ & 30.861 & 0.00 \\
FOR & 38.500 & 0.00 \\
$C A R B$ & 9.379 & 0.00 \\
TEMP & 23.942 & 0.00 \\
PEON & 26.737 & 0.00 \\
GDP & 1.179 & 0.12 \\
TRADE & 8.368 & 0.00 \\
INFL & 27.511 & 0.00 \\
RATE & 12.601 & 0.00 \\
\hline
\end{tabular}

This table shows the panel unit root test of all variables, which is obtained via using STATA 15. The fisher-test follows the research of Dong et al. (2018), and the original hypothesis is that there exists a panel unit root

have both increased faster than that decades ago. The rates of increase, the frequency, and total economic losses also vary greatly for different types of countries.

Table 1 displays the summary of all variables. It is noted that the relevant variables are adjusted in units to ensure convenient interpretation of regression coefficients. The results indicate that the standard deviations of most variables are small, except for the economic losses of natural disasters $(D I S A)$ and the ratio of trade to GDP (TRADE). The maximum and minimum of $B A D L$ are 59.757 and 0.082 , respectively, and the mean and standard deviation are 6.566 and 6.960, revealing that non-performing loans in most countries are concentrated near the mean and are 
stable. Moreover, the mean and standard deviation of ASSR are, respectively, 10.341 and 3.877 , in which the maximum and minimum are 1.490 and 24.849 , revealing that volatility is not big. However, the mean of index DISA is smaller than 1, because many countries have not suffered from natural disasters. However, the standard deviation of DISA is 15.357 , which is smaller than the difference between maximum and minimum, showing stability of the variable. We find that the standard deviations of FOR, CARB, and TEMP are 0.021, 5.523, and 0.611, respectively, which are all small. Finally, although the standard deviation of TRADE is the biggest at 57.253, the difference between maximum and minimum is 356.856, indicating the variable fluctuates very little. The standard deviations of other control variables are smaller than 10 , showing that all variables are centralized.

\section{Empirical results}

\subsection{Unit root test}

Our paper shows the unit root test, so as to verify the robustness of empirical results. Table 2 reveals that the Fisher tests of all variables, except for GDP, are significant, indicating that all variables are stationary. It is noted that the LLC test, IPS test, and other tests are not suitable in this paper, because they need balanced panel data (Feng et al. 2019; Wei et al. 2020). Hence, the data can be used for the following regression, such as the panel model and mediating effect model.

\subsection{Empirical results and analysis}

The model typically uses the estimation of simultaneous equations through time series data or cross-sectional data (Miao et al. 2019). However, a large number of articles employ stepwise regression to estimate panel data (García-Sánchez et al. 2019). Our paper utilizes the three-stage least square method, one of the simultaneous equations, to study the effect of climate change on bank performance by considering the panel fixed effect model. First, we verify the total effect of climate change on bank performance, such as the non-performing loan ratio and the ratio of capital to assets. Second, we test the mediating effect or indirect effect through the mediating effect model. Finally, we divide the full sample into high-income and lowincome countries, aiming to find the differences in effects between the two samples.

(1) The total effect of climate change on bank performance.

Table 3 displays the estimation results of the total effect of climate change on banks' non-performing loan ratio and the ratio of capital to assets of the whole sample at the national level. First, Columns (1) to (3) are the estimation results of banks' non-performing loan ratio, revealing that there may be an effect of climate change on BADL. The coefficient of FOR in Column (1) is -59.907 and significant at $1 \%$ level, showing a strong negative effect of forest land on the non-performing loan ratio. Column (2) indicates that the coefficient of $C A R B$ is 0.174 , but not significant. In addition, carbon dioxide emissions have no effect on the bank non-performing 
Table 3 Estimation result of BADL and ASSR: total effect

\begin{tabular}{|c|c|c|c|c|c|c|}
\hline Dependent Variable & (1) & (2) & (3) & (4) & (5) & (6) \\
\hline & $B A D L$ & $B A D L$ & $B A D L$ & $A S S R$ & $A S S R$ & $A S S R$ \\
\hline \multirow[t]{2}{*}{ FOR } & $-57.907 * * *$ & & & -0.950 & & \\
\hline & $(-6.226)$ & & & $(-0.188)$ & & \\
\hline \multirow[t]{2}{*}{$C A R B$} & & 0.174 & & & $-0.241 * * *$ & \\
\hline & & (1.391) & & & $(-3.535)$ & \\
\hline \multirow[t]{2}{*}{ TEMP } & & & $1.938 * * *$ & & & $0.419 * *$ \\
\hline & & & $(4.900)$ & & & $(2.121)$ \\
\hline \multirow[t]{2}{*}{ PEON } & $-9.314 * * *$ & 8.296 & -5.494 & -0.155 & $-{ }^{-} 21.956^{* * * *}$ & $-7.916^{* *}$ \\
\hline & $(-2.948)$ & $(0.692)$ & $(-0.731)$ & $(-0.093)$ & $(-3.351)$ & $(-2.129)$ \\
\hline \multirow[t]{2}{*}{$G D P$} & $-0.954 * * *$ & $-0.772 * * *$ & $-1.090 * * *$ & $-{ }^{-} 0.829 * * *$ & $-1.011^{* * *} *$ & $-0.905^{* * *}$ \\
\hline & $(-8.699)$ & $(-5.856)$ & $(-9.299)$ & $(-13.562)$ & $(-13.655)$ & $(-14.875)$ \\
\hline \multirow[t]{2}{*}{$T R A D E$} & $0.014 * * *$ & $0.012 * *$ & $0.016 * * *$ & 0.003 & 0.003 & $0.007 * * *$ \\
\hline & $(3.501)$ & $(2.551)$ & $(3.648)$ & $(1.542)$ & $(1.253)$ & $(3.471)$ \\
\hline \multirow[t]{2}{*}{$I N F L$} & $-0.053^{*}$ & -0.037 & -0.029 & $0.062 * * *$ & $0.081 * * *$ & $0.051 * * *$ \\
\hline & $(-1.772)$ & $(-1.087)$ & $(-0.908)$ & (3.867) & (4.309) & $(3.170)$ \\
\hline \multirow[t]{2}{*}{ RATE } & $-0.048^{*}$ & -0.009 & $-0.068^{* *}$ & $0.055^{* * *}$ & $0.062 * * *$ & $0.045 * * *$ \\
\hline & $(-1.746)$ & $(-0.266)$ & $(-2.253)$ & (3.767) & (3.559) & (3.027) \\
\hline \multirow[t]{2}{*}{ Constant } & $9.306 * * *$ & $6.668 * * *$ & $5.515 * * *$ & $10.762 * * *$ & $10.828 * * *$ & $10.267 * * *$ \\
\hline & $(15.979)$ & (10.922) & $(8.459)$ & $(34.660)$ & $(33.440)$ & $(32.414)$ \\
\hline Obs & 1216 & 859 & 1140 & 1157 & 817 & 1078 \\
\hline Chi2 & 42.015 & 39.568 & 50.766 & 61.156 & 33.012 & 44.979 \\
\hline$F$ test & 6.792 & 5.064 & 7.296 & 5.222 & 3.905 & 6.049 \\
\hline
\end{tabular}

Here, we use the fixed panel model by considering the panel fixed effect model. Columns (1) to (6) refer to Eq. (9). ${ }^{* * *},{ }^{* *}$, and ${ }^{*}$ indicate statistical significance at the $1 \%, 5 \%$, and $10 \%$ levels, respectively

loan ratio. We also find that the effect of TEMP on BADL is 1.938 and also significant at the $1 \%$ level-namely, temperature change may increase the non-performing loan ratio.

Second, this paper examines the influence of climate change on the ratio of capital to assets. From Column (4), we find that FOR has a negative influence on ASSR and is not significant. The coefficient between $C A R B$ and $A S S R$ is -0.241 and significant at the $1 \%$ level, showing that the effect of carbon dioxide on the ratio of capital to assets is negative. In addition, the impact of TEMP and ASSR in Column (6) is 0.419 and also significant at $1 \%$ level. It is clear that temperature change has a positive influence on a bank's ratio of capital to assets. In short, the above conclusions may show the impact of different climate change on bank performance.

The existing literature only studies the impact of climate change on the performance of agriculture and manufacturing (Hassan 2010) and reaches the conclusion that extreme temperatures, droughts, and floods lead to serious damage to farming systems and agro-climates, especially for Africa. Whether or not climate change can 
Table 4 Estimation result of $B A D L$ : mediating effect

\begin{tabular}{|c|c|c|c|c|c|c|}
\hline Dependent Variable & (1) & (2) & (3) & (4) & (5) & (6) \\
\hline DISA & DISA & $\begin{array}{l}B A D L \\
270.131 * * \\
(2.149)\end{array}$ & $D I S A$ & $\begin{array}{l}B A D L \\
44.991 \\
(1.375)\end{array}$ & $D I S A$ & $\begin{array}{l}B A D L \\
361.309 * * * \\
(2.923)\end{array}$ \\
\hline FOR & $\begin{array}{l}-0.214 * * \\
(-2.407)\end{array}$ & & & & & \\
\hline$C A R B$ & & & $\begin{array}{l}0.004 * * * \\
(7.046)\end{array}$ & & & \\
\hline TEMP & & & & & $\begin{array}{l}0.005 * * * \\
(3.275)\end{array}$ & \\
\hline PEON & $\begin{array}{l}-0.379 * * * \\
(-14.073)\end{array}$ & $\begin{array}{l}93.135^{* *} \\
(1.975)\end{array}$ & $\begin{array}{l}0.049 \\
(0.955)\end{array}$ & $\begin{array}{l}6.164 \\
(0.594)\end{array}$ & $\begin{array}{l}-0.058 * * \\
(-2.017)\end{array}$ & $\begin{array}{l}15.091 \\
(1.152)\end{array}$ \\
\hline$G D P$ & $\begin{array}{l}0.001 \\
(0.704)\end{array}$ & $\begin{array}{l}-1.132 * * * \\
(-3.718)\end{array}$ & $\begin{array}{l}0.001 * * \\
(2.522)\end{array}$ & $\begin{array}{l}-0.829 * * * \\
(-6.353)\end{array}$ & $\begin{array}{l}0.000 \\
(0.655)\end{array}$ & $\begin{array}{l}-1.200 * * * \\
(-5.195)\end{array}$ \\
\hline TRADE & & $\begin{array}{l}0.014 * * * \\
(3.453)\end{array}$ & & $\begin{array}{l}0.011^{* *} \\
(2.528)\end{array}$ & & $\begin{array}{l}0.017 * * \\
(2.227)\end{array}$ \\
\hline$I N F L$ & & $\begin{array}{l}-0.052 \\
(-1.601)\end{array}$ & & $\begin{array}{l}-0.037 \\
(-1.080)\end{array}$ & & $\begin{array}{l}-0.032 \\
(-0.848)\end{array}$ \\
\hline RATE & & $\begin{array}{l}-0.048^{*} \\
(-1.741)\end{array}$ & & $\begin{array}{l}-0.009 \\
(-0.283)\end{array}$ & & $\begin{array}{l}-0.067 * * \\
(-2.141)\end{array}$ \\
\hline Constant & $\begin{array}{l}0.006 \\
(1.557)\end{array}$ & $\begin{array}{l}7.715^{* * * *} \\
(9.199)\end{array}$ & $\begin{array}{l}-0.002 * \\
(-1.776)\end{array}$ & $\begin{array}{l}6.782 * * * \\
(11.176)\end{array}$ & $\begin{array}{l}-0.009 * * * \\
(-4.478)\end{array}$ & $\begin{array}{l}8.616^{* * * *} \\
(12.584)\end{array}$ \\
\hline Mediating effect & $-57.808^{*}$ & $0.180^{*}$ & $1.807^{* *}$ & & & \\
\hline Sobel test & -1.703 & 1.658 & 2.181 & & & \\
\hline Obs & 1216 & 1216 & 859 & 859 & 1140 & 1140 \\
\hline Chi2 & 56.249 & 61.281 & 62.202 & 65.266 & 49.288 & 48.321 \\
\hline F test & 6.792 & 5.064 & 7.296 & 7.764 & 3.667 & 3.501 \\
\hline
\end{tabular}

Here, we use the three-stage least square method considering the panel fixed effect model. Columns (1), (3), and (5) refer to Eq. (10). Columns (2), (4), and (6) refer to Eq. (11). ${ }^{* * *},{ }^{* *}$, and ${ }^{*}$ indicate statistical significance at the $1 \%, 5 \%$, and $10 \%$ levels, respectively

affect bank performance is still a puzzle, because a bank is the place to manage capital, and rising temperatures, like other climate phenomena, do not seem to have any correlation. Farmers, plants, and livestock are directly affected by climate change such as temperatures, forest land, grass land, precipitation, and lakes. However, our conclusion is that climate change does have a comparative significant effect on bank performance. Why? The above analysis shows that climate change can affect agriculture, manufacturing. People deposit their money in a bank and obtain loans from the bank for treatment, investing, and so on (Pennacchi 2006; Wen and Chang, 2015). Furthermore, enterprises borrow money from banks or other financial institutions in order to purchase production equipment, develop new markets, conduct research and development, etc. In short, people and enterprises suffer economic losses and even bankruptcy, and they sometimes turn to banks for help so as to survive (Cortés and Strahan, 2017). Therefore, climate change does not directly affect 
bank performance, but has an indirect effect on the deposits, loans, and capital of the bank in other ways.

(2) The mediating effect of climate change on banks' non-performing loan ratio.

The above analysis indicates that it is likely that climate change influences the development of enterprises and the lives of people through natural disasters, which have an effect on their deposits and loans at banks. Therefore, this paper tests the mechanism for the economic losses of natural disasters.

Table 4 displays the direct effect and indirect effect of climate change on banks' non-performing loan ratio more clearly. First, we see the mediating effect of forest land through natural disasters. The coefficients of FOR and DISA in Column (1) and Column (2) are, respectively, -0.214 and 270.131 and significant at the $5 \%$ level, showing that forest area reduces the economic losses of natural disasters, and the economic losses of natural disasters raise banks' non-performing loan ratio. Moreover, the indirect effect denotes the path from FOR to BADL through DISA-namely, $0.214 \times 270.131=-57.808$ - and the Sobel test is significant at the $10 \%$ level, which shows the existence of the mediating effect of forest land on the non-performing loan ratio. The ratio of indirect effect to total effect is 0.998 (I-57.808/-57.907I). According to the traditional mediating effect model, the impact of climate change on bank performance through natural disasters accounts for $99.8 \%$, while the total effect exists. However, this paper assumes that the total effect does not exist. It is obvious that an increase of one unit in the ratio of forest land to national area will reduce the non-performing loan ratio by 57.808 units through natural disasters.

This paper next studies the mediating effect of carbon dioxide emissions. We conclude that the effects of CAR on DISA as well as DISA on BADL are 0.004 and 44.991, respectively, as shown in Columns (3) to (4) and are significant at the $1 \%$ level for Eq. (10). The mediating effect considering the economic losses of natural disasters is $0.180(0.004 \times 44.991)$, and the Sobel test is also significant at the $10 \%$ level. The ratio of the mediating effect to total effect is $1.034(|0.180 / 0.174|)$. All the results show a mediating effect of carbon dioxide emissions on the non-performing loan ratio. Finally, the coefficients of TEMP and DISA in Column (5) and (6) are, respectively, 0.005 and 361.309 and significant at the $1 \%$ level, showing that temperature change has a positive effect on natural disasters, and natural disasters also affect the non-performing loan ratio positively and significantly. The mediating effect is 1.807 , and the ratio is 0.932 (11.807/1.938I) and is also significant. The conclusions are similar to Brahmana et al. (2016). The above analysis shows that an increase of one unit in the ratio of carbon dioxide emissions to national area or temperature change will, respectively, raise the non-performing loan ratio by 0.180 units or 1.807 units through natural disasters, while there are no total effects of $C A R B$ and TEMP on BADL.

Why does there exist a mediating effect of climate change on the non-performing loan ratio of banks through natural disasters? First, forests can absorb carbon dioxide and thus prevent the greenhouse effect (Williams 2013). Moreover, forests can also protect the soil and prevent desertification, which help reduce floods, debris flow, and the harmful aftermath of storms. In short, a country with large forest land should see a decline in deaths and economic losses from natural disasters, such as floods, storms, extreme temperatures, etc. 
Table 5 Estimation result of ASSR: mediating effect

\begin{tabular}{|c|c|c|c|c|c|c|}
\hline Dependent Variable & (1) & (2) & (3) & (4) & (5) & (6) \\
\hline & DISA & $A S S R$ & $D I S A$ & $A S S R$ & $D I S A$ & $A S S R$ \\
\hline \multirow[t]{2}{*}{$D I S A$} & & -6.042 & & $-65.575^{* * *}$ & & $-46.460 *$ \\
\hline & & $(-0.175)$ & & $(-2.735)$ & & $(-1.747)$ \\
\hline \multirow[t]{2}{*}{ FOR } & -0.155 & & & & & \\
\hline & $(-1.480)$ & & & & & \\
\hline \multirow[t]{2}{*}{$C A R B$} & & & $0.004 * * *$ & & & \\
\hline & & & (3.793) & & & \\
\hline \multirow[t]{2}{*}{ TEMP } & & & & & $0.009 * * *$ & \\
\hline & & & & & (3.473) & \\
\hline \multirow[t]{2}{*}{ PEON } & $0.380 * * *$ & 2.146 & 0.028 & $-20.039 * * *$ & 0.059 & -4.809 \\
\hline & $(12.251)$ & $(0.167)$ & $(0.310)$ & $(-2.662)$ & (1.303) & $(-1.061)$ \\
\hline \multirow[t]{2}{*}{$G D P$} & -0.001 & $-0.837 * * *$ & $0.002 * *$ & $-0.876^{* * *}$ & -0.001 & - \\
\hline & $(-1.166)$ & $(-9.833)$ & $(2.227)$ & $(-9.189)$ & $(-0.768)$ & $\begin{array}{r}0.923^{*} \\
(-10.846)\end{array}$ \\
\hline \multirow[t]{2}{*}{ TRADE } & & 0.003 & & 0.003 & & $0.007 * * *$ \\
\hline & & $(1.507)$ & & $(1.211)$ & & $(2.695)$ \\
\hline \multirow[t]{2}{*}{$I N F L$} & & $0.063 * * *$ & & $0.081 * * *$ & & $0.053^{* * *}$ \\
\hline & & $(3.547)$ & & (4.309) & & (3.127) \\
\hline \multirow[t]{2}{*}{$R A T E$} & & $0.055^{* * *} *$ & & $0.062 * * *$ & & $0.044 * * *$ \\
\hline & & $(3.768)$ & & $(3.553)$ & & $(2.993)$ \\
\hline \multirow[t]{2}{*}{ Constant } & -0.001 & $10.752 * * *$ & $-0.005^{* *}$ & $10.492 * * *$ & $0.014 * * *$ & $10.955 * * *$ \\
\hline & $(-0.331)$ & $(36.323)$ & $(-2.232)$ & (30.074) & $(4.705)$ & (37.834) \\
\hline Mediating effect & 0.937 & $-0.263^{* *}$ & $-0.418^{*}$ & & & \\
\hline Sobel test & 0.174 & -2.218 & -1.651 & & & \\
\hline Obs & 1157 & 1157 & 817 & 817 & 1078 & 1078 \\
\hline Chi2 & 66.249 & 71.281 & 52.202 & 55.266 & 39.288 & 38.321 \\
\hline$F$ test & 7.792 & 7.064 & 8.296 & 5.764 & 7.667 & 4.501 \\
\hline
\end{tabular}

Same as Table 4

Second, Van-Aalst (2006) pointed out that CO2 emissions are the main greenhouse gas and come from fossil fuels, like coal and oil, which are used by humans for life and production. The $\mathrm{CO} 2$ emissions increase temperature by changing the atmosphere, which will cause glaciers to melt, extreme temperatures, precipitations, droughts, and so on. Moreover, $\mathrm{CO} 2$ affects landslides, earthquakes, and storms by changing atmospheric pressure and temperature (Zoback and Gorelick, 2012). Therefore, carbon dioxide emissions have a significant effect on death and economic losses from natural disasters. 
Third and finally, temperature is the most sensitive factor of climate change. Temperature is the direct reason for droughts and floods. ${ }^{8}$ The world has experienced the most obvious climate change in the last two decades. For example, the difference between the highest temperature and the lowest temperature is becoming greater, and the duration is also increasing and advancing. The temperature also directly accelerates the melting speed of icebergs in the north and south poles and in high mountains and can increase sea levels and change ocean currents. The rapid outbreak of COVID-19 in 2019 may be caused by increasing temperatures, as the virus is adapted to warm temperatures (Harmooshi et al. 2020).

According to the above analysis, natural disasters lead to the deaths and unhealthy lives of residents as well as production losses and bankruptcy of enterprises. For enterprises and individuals who have loans from banks before the occurrence of natural disasters, they may not be able to repay them within the prescribed period due to property losses after natural disasters occur (Amin et al. 2019). When the country suffers from serious natural disasters, especially for a large number of deaths and the collapse of enterprises, the government typically assists people and enterprises with financial funding in order to prevent unrest and puts pressure on banks and other financial institutions to help them, too. This may lead to an increase of bank loans in the event of natural disasters and a rise in non-performing loans at banks since the people and enterprises cannot repay the loan in a short time. Therefore, climate change has an influence on the non-performing loan ratio of banks through natural disasters.

(3) The mediating effect of climate change on a bank's ratio of capital to assets.

Banks' ratio of capital to assets is another index to measure the ability to overcome risk (Konishi and Yasuda, 2004). A bank's ability to deal with risk is stronger when the value of this index is larger. Natural disasters and damage to agricultural and manufacturing caused by climate change affect bank deposits and loans. Banks may not have normal operations, because they cannot get sufficient funds from the repayment of loans and deposit when their capital is too low. Therefore, it is necessary to study the impact of climate change on the ratio of bank capital to assets through natural disasters.

Table 5 reveals the estimation results of the ratio of bank capital to assets, which also almost show significance of the coefficients. First, the impact of FOR on DISA in Column (1) is -0.155 , and the coefficient of DISA in Column (2) is -6.042. Both are insignificant, which arrive at the conclusion that the mediating effect is 0.937 and is insignificant, too, showing that forest land cannot affect the ratio of capital to assets via natural disasters. The ratio of mediating effect to total effect is 0.986 $(|0.937 /-0.950|)$. It reveals that a rise of one unit in the ratio of forest land to national area can increase 0.937 units of the ratio of bank capital to assets through DISA, but this path is insignificant.

\footnotetext{
${ }^{8}$ Source: Climate Change Indicators in the United States in 2016, proposed by United States Environmental Protection Agency.
} 
Table 6 Estimation result of $B A D L$ : low-income vs high-income

\begin{tabular}{|c|c|c|c|c|c|c|}
\hline Subsample A & $\begin{array}{l}\text { Low-income coun- } \\
\text { tries }\end{array}$ & & & & & \\
\hline Dependent & (1) & (2) & (3) & (4) & (5) & (6) \\
\hline & DISA & $B A D L$ & DISA & $B A D L$ & DISA & $B A D L$ \\
\hline DISA & & $\begin{array}{l}-3966.304 * \\
(-1.943)\end{array}$ & & $\begin{array}{l}-64,361.545 \\
(-0.402)\end{array}$ & & $\begin{array}{l}7927.016 \\
(1.174)\end{array}$ \\
\hline FOR & $\begin{array}{l}-0.019 * * \\
(-2.044)\end{array}$ & & & & & \\
\hline$C A R B$ & & & $\begin{array}{l}-0.000 \\
(-0.008)\end{array}$ & & & \\
\hline TEMP & & & & & $\begin{array}{l}-0.001 \\
(-1.044)\end{array}$ & \\
\hline Mediating effect & 75.360 & 64.362 & -7.927 & & & \\
\hline Sobel test & 1.401 & 0.010 & -0.780 & & & \\
\hline$D I S A$ & & $\begin{array}{l}153.192 \\
(1.638)\end{array}$ & & $\begin{array}{l}24.791 \text { *** } \\
(2.839)\end{array}$ & & $\begin{array}{l}163.513 * * \\
(2.359)\end{array}$ \\
\hline FOR & $\begin{array}{l}-0.249^{*} \\
(-1.881)\end{array}$ & & & & & \\
\hline$C A R B$ & & & $\begin{array}{l}0.004 * * * \\
(5.355)\end{array}$ & & & \\
\hline TEMP & & & & & $\begin{array}{l}0.007 * * * \\
(3.216)\end{array}$ & \\
\hline Mediating effect & -38.145 & $0.099 * *$ & $1.145^{*}$ & & & \\
\hline Sobel test & -1.435 & 2.508 & 1.902 & & & \\
\hline
\end{tabular}

Same as Table 4. High-income countries include 58 countries with high- and medium high-income via the classification of the World Bank database. Low-income countries encompass 69 countries with lowand medium low-income through the classification of the World Bank database

Second, the coefficient of $C A R B$ in Column (3) is 0.004 , and the effect of DISA on ASSR in Column (4) is -65.575 . Both are significant at the $1 \%$ level. The mediating effect is $-0.263(0.004 \times-65.575)$, and the Sobel test is -2.218 . This is significant at the 5\% level, indicating that carbon dioxide emissions decrease the ratio of the bank capital to assets through natural disasters. The indirect effect ratio is 1.091 $(|-0.263 /-0.241|)$. We find that the ratio of bank capital to assets decreases by 0.263 units, while the ratio of carbon dioxide emissions to national area increases by 1 unit after considering the mediating effect of natural disasters.

Third and finally, by considering temperature change, the effect of TEMP on $D I S A$ is 0.009 and significant at the $1 \%$ level. Moreover, the impact of DISA on $A S S R$ is negative at -46.460 and significant. Hence, temperature change raises the economic losses of natural disasters and has a negative effect on the ratio of bank capital to assets. The ratio of the indirect effect is $0.997(|-0.418 / 0.419|)$, and the Sobel test is -1.651 , which is also significant. Temperature change has a strong effect 
on the ratio of bank capital to assets through natural disasters. A decline of ASSR by 0.418 units comes from a temperature change increase of 1 unit after considering the mediating effect of DISA.

The analysis in the previous section shows that climate change has a significant effect on deaths and economic losses of natural disasters. However, the coefficient of climate change on natural disasters in Table 5 is different from that of Table 4, and the reason is that the sample is changed due to a lack of the dependent variable. In addition, natural disasters impact the production of enterprises and the lives of humans. Loayza et al. (2012) pointed out that natural disasters decrease human capital accumulation via sick, lives lost, and unemployment, which also have an influence on bank performance. A bank cannot get money from the loans and deposits of humans and enterprises that are affected by disasters, thus hindering a bank's normal operations. Serious natural disasters may also cause social unrest and soaring prices. People may also withdraw their savings to maintain their livelihood, and enterprises may also close down (Klomp 2014). The free capital of a bank will drop, which cannot afford the salary and decline the profit. National debt issued by the government is difficult to recover after the occurrence of natural disasters, thus raising national debt further. In order to repay debt, a large amount of paper money may be issued by the government, leading to depreciation and inflation, and the capital of banks will become less and less. Therefore, natural disasters have a mediating effect of climate change on the ratio of bank capital to assets.

(4) Classification by low-income and high-income countries.

Residents in low-income countries have a hard life. The income they earn is basically used for their daily life, and they seldom borrow from and make deposits into banks. However, people in high-income countries have surplus money to invest, and banks of high-income countries are properly developed and can provide loans to people and enterprises. Therefore, natural disasters, caused by climate change, affect humans and enterprises and impact bank performance in a more significant way in high-income countries than in low-income countries. Hence, it is necessary to study the different mediating effects of climate change on bank performance through natural disasters by considering income heterogeneity.

Kellenberg and Mobarak (2008) indicated that a country with different incomes suffers from varying damage risks from natural disasters. Generally speaking, rising income can decrease deaths and economic losses due to natural disasters. Ghosh (2016) also reached the conclusion that bank performances, such as return on assets, profits, and cost efficiency, are different when the income level varies. Hence, this paper follows the research of Koyanagi et al. (2019) and divides countries into two subsamples: high-income countries, including high-income and medium highincome countries due to the World Bank; and low-income countries, including lowincome and medium low-income countries also due to the World Bank. We now explore the different effects of climate change on bank performance in low- and high-income countries through natural disasters.

First, the estimation results of low-income countries appear in Table 6. We find that all the mediating effects are insignificant. For example, although the coefficients of FOR and DISA in Columns (1) and (2) are 0.019 and -3,966.304, respectively, which are significant at the 5\% level, the indirect effect is 75.360 , 
and the Sobel test is 1.401 . The conclusion shows that forest land can decrease the economic losses of natural disasters in low-income countries, which may be caused by their poor GDP, infrastructure, and development, and natural disasters decrease banks' non-performing loan ratio. Moreover, carbon dioxide emissions have an insignificantly negative impact on natural disasters. The coefficient of DISA in Column (4) is $-64,361$, which means that the mediating effect is 64.362 , and the Sobel test is 0.010 , and the mediating effect is insignificant, too. Thus, natural disasters do not mediate the effect of climate change on the non-performing loan ratio in low-income countries. Furthermore, the coefficients of TEMP and DISA in Columns (5) and (6) are, respectively, -0.001 and 7,927.016, and both parameters are insignificant. Hence, the indirect effect of temperature change in low-income countries is $-7.927(-0.001 \times 7927.016)$ and also insignificant. The conclusion is that the mediating effect of climate change on the non-performing loan ratio in low-income countries is weak, and the mediating effect of natural disasters does not exist.

Second, Panel B in Table 6 shows the estimation result of the mediating impact of climate change on the non-performing loan ratio through natural disasters. We note that there is a strongly positive mediating influence of different climate changes on BADL. The coefficient of FOR in Column (1) is -0.249 and is significant at the $10 \%$ level. In addition, the economic loss of natural disasters has a positive impact (153.192) on $B A D L$. The indirect effect is -38.145 , which is not insignificant, but just negative. It reveals that forest land does not affect banks' non-performing loan ratio via natural disasters. However, the coefficients of CARB and DISA in Columns (3) and (4) are, respectively, 0.004 and 24.791, and both are significant at the $1 \%$ level. Moreover, the value of mediator DISA in high-income countries is 0.099 and also significant at 5\%. We conclude that carbon dioxide increases the non-performing loan ratio, and there is an obvious mediating effect $(0.004 \times 24.791=0.099)$ of $C A R B$ on $B A D L$ through DISA. Finally, the influence of temperature change on the economic losses of natural disasters is 0.007 and significant at the $1 \%$ level. Furthermore, there is a significantly positive impact (163.513) of TEMP on BADL. The mediating effect is $1.145(0.007 \times 163.513)$, and the Sobel test is 1.902 , which is also significant. The above conclusions indicate that there exists a significant mediating impact of climate change on banks' non-performing loan ratio through natural disasters.

Why is there such a big difference between high- and low-income countries? The reason may be in the differences of their financial development, infrastructure, residents' livelihood, and enterprise development. First, low-income levels mean slow development of a country, showing that it is mainly agriculture or low-end industry, and its carbon dioxide emissions, caused by manufacturing and humans, are not much. Therefore, there may be a weak effect of carbon dioxide emissions on the deaths and economic losses of natural disasters in such countries. Temperature change is caused by many factors, including carbon dioxide emissions and other greenhouse gases, which also have an insignificant effect on natural disasters (Herold et al. 2017). In addition, forest land can directly prevent natural disasters, as it can consolidate soil and resist strong winds and floods. Therefore, forest land 
Table 7 Estimation result of man-made disasters: mediating effect

\section{Independent variable:}

$B A D L$

Dependent Variable (1)

(4)

(5)

(6)

\begin{tabular}{lll} 
& $M D I S A$ & $B A D L$ \\
\hline MDISA & & $4.838^{* * * *}$ \\
& & $(4.011)$ \\
FOR & $-11.059^{* * * *}$ & \\
& $(-4.258)$ &
\end{tabular}

$C A R B$

TEMP

MDISA


$1.647 * * *$
$(8.213)$

$B A D L \quad M D I S A \quad B A D L$

$0.129 * * \quad 4.530 *$

(2.437)

\begin{tabular}{|c|c|c|c|c|c|c|}
\hline TEMP & & & & & $\begin{array}{l}0.250 \\
(1.397)\end{array}$ & \\
\hline Mediating effect & $-53.503 * * *$ & $0.053 * *$ & 1.133 & & & \\
\hline Sobel test & -2.919 & 2.336 & 1.097 & & & \\
\hline & $\begin{array}{l}\text { Independent variable: } \\
\quad A S S R\end{array}$ & & & & & \\
\hline Dependent Variable & (1) & (2) & (3) & (4) & (5) & (6) \\
\hline & MDISA & $A S S R$ & MDISA & $A S S R$ & MDISA & ASSR \\
\hline$M D I S A$ & & $\begin{array}{l}-0.099 * * \\
(-1.973)\end{array}$ & & $\begin{array}{l}-0.071 * * \\
(-2.064)\end{array}$ & & $\begin{array}{l}-0.277 * \\
(-1.649)\end{array}$ \\
\hline FOR & $\begin{array}{l}-13.150 * * * \\
(-2.960)\end{array}$ & & & & & \\
\hline$C A R B$ & & & $\begin{array}{l}1.093 * * * \\
(14.706)\end{array}$ & & & \\
\hline TEMP & & & & & $\begin{array}{l}0.272 \\
(1.482)\end{array}$ & \\
\hline Mediating effect & $1.302 *$ & $-0.077 * *$ & -0.075 & & & \\
\hline Sobel test & 1.642 & -2.044 & -1.102 & & & \\
\hline
\end{tabular}

Same as Table 4

decreases the deaths and economic losses of natural disasters in both low- and highincome countries.

Second, we find that the effect of natural disasters on bank performance in lowincome countries is insignificant. The reason is that the development of financial institutions in low-income countries is slower than that in high-income countries. Furthermore, residents with low income will typically not borrow or invest from a bank, because they need to live on their current wages. Enterprises, with poor technology and equipment in low-income countries, are only engaged in low-end agriculture, raw material processing, and production industries. The poor life and production of humans and enterprises in low-income countries may be not affected when natural disasters occur. However, people with high incomes and enterprises with high technology and production are willing to borrow from financial institutions. These loans cannot be repaid in the short term, thus leading to higher 
non-performing loans and worsening bank performance when disasters happen. Therefore, natural disasters do not mediate the effect of climate change on bank performance in low-income countries, but a mediating effect of climate change exists on bank performance through natural disasters in high-income countries.

\subsection{Robustness test}

The above results on the mediating effect of estimation still have some shortcomings to be improved. For instance, are the variable of economic losses of natural disasters appropriate? Is the method of simultaneous equations suitable in this paper? If we use another index or measurement, then can we arrive at the same conclusions? Hence, we need a robustness test to study the rationality of the conclusions. First, this paper analyzes man-made disasters. Second, this paper uses deaths of natural disasters (DISAD) and deaths of man-made disasters (MDISAD) instead of economic losses of natural disasters and man-made disasters. Third, we collect the ratio of loan loss provisions to total assets $(B L L P)$ to measure the bank loss. Finally, we utilize stepwise regression by considering the fixed effect panel model to test the indirect effect of climate change on bank performance through the economic losses of natural disasters.

(1) Further analysis: man-made disasters.

Disasters consist of natural disasters caused by mother nature and man-made disasters caused by humans. It is obvious from the above analysis that climate change affects the cost of natural disasters, which damage enterprises' production and lives of residents. When enterprises and residents are not able to repay bank debts, bank sector performance declines.

Climate change can also affect man-made disasters. Extreme high temperature is not properly conducive to the operation of factory equipment and parts of motor vehicles, which may result in industrial accidents and transport accidents, such as factory explosion, spontaneous car engine combustion, and so on (Labovská et al. 2014). Greenhouse gases and forests both change the atmospheric pressure and the absorption of solar heat and eventually affect the temperature. Severe weather phenomena, such as fog, sandstorms, haze, and strong winds, will hinder people's sight, which could cause traffic accidents ( $\mathrm{Lu}$ et al. 2020). Moreover, forest land can effectively reduce inclement weather such as sandstorms, haze, and strong winds. Rainstorms and blizzards also can cause traffic accidents through slippery or icy roads, and rainwater can lead to electrical short circuits that result in industrial accidents. Hence, this paper follows the research of Hong (2017) and collects data of manmade disasters from EMDAT (international disasters database), which consists of industrial accidents, transport accidents, and miscellaneous accidents. According to the above measurement, we choose economic losses from industrial accidents, transport accidents, and miscellaneous accidents as the cost of man-made disasters $(M D I S A)$ to study the mediating effect of climate change on bank performance via man-made disasters.

First, the estimation results of the non-performing loan ratio are displayed in Table 7. We obtain that all the mediating effects are insignificant except for 
Table 8 Estimation result of $B A D L$ via changing the mediating variable

Mediating variable:

DISAD

\begin{tabular}{|c|c|c|c|c|c|c|}
\hline \multirow[t]{2}{*}{ Dependent Variable } & (1) & (2) & (3) & (4) & (5) & (6) \\
\hline & $D I S A D$ & $B A D L$ & DISAD & $B A D L$ & DISAD & $B A D L$ \\
\hline$D I S A D$ & & $\begin{array}{l}29.815^{* * * *} \\
(5.895)\end{array}$ & & $\begin{array}{l}66.476 \\
(0.226)\end{array}$ & & $\begin{array}{l}18.206 * * \\
(2.159)\end{array}$ \\
\hline FOR & $\begin{array}{l}-1.935^{*} \\
(-1.752)\end{array}$ & & & & & \\
\hline$C A R B$ & & & $\begin{array}{l}0.003 \\
(0.287)\end{array}$ & & & \\
\hline TEMP & & & & & $\begin{array}{l}0.106^{* *} \\
(2.274)\end{array}$ & \\
\hline Mediating effect & $-57.692 *$ & 0.199 & $1.929 *$ & & & \\
\hline Sobel test & $\begin{array}{l}-1.680 \\
\text { Mediating variable: } \\
\quad M D I S A D\end{array}$ & 0.178 & 1.766 & & & \\
\hline Dependent Variable & (1) & (2) & (3) & (4) & $(5)$ & (6) \\
\hline & MDISAD & $B A D L$ & $M D I S A D$ & $B A D L$ & MDISAD & $B A D L$ \\
\hline MDISA & & $\begin{array}{l}1.429 * * * \\
(4.110)\end{array}$ & & $\begin{array}{l}0.112^{* *} \\
(2.380)\end{array}$ & & $\begin{array}{l}8.911 \\
(0.958)\end{array}$ \\
\hline FOR & $\begin{array}{l}-49.767 * * * \\
(-3.281)\end{array}$ & & & & & \\
\hline$C A R B$ & & & $\begin{array}{l}8.184 * * * \\
(16.176)\end{array}$ & & & \\
\hline TEMP & & & & & $\begin{array}{l}0.404 * \\
(1.643)\end{array}$ & \\
\hline Mediating effect & $-71.117^{* * *}$ & $0.917 * *$ & 3.600 & & & \\
\hline Sobel test & -2.564 & 2.355 & 0.828 & & & \\
\hline
\end{tabular}

Same as Table 4

temperature. For instance, the coefficients of FOR and MDISA in Columns (1) and (2) are -11.059 and 4.838 , respectively, which are both significant. In addition, the mediating effect is -53.503 , and the Sobel test is -2.919 , and the mediating effect is significant at the $1 \%$ level. The result indicates that forest land can decrease the economic losses from man-made disasters, and that man-made disasters increase banks' non-performing loan ratio, which may cause enterprises and residents to suffer from man-made disasters and thus be unable to repay loans. Furthermore, the coefficients of CARB and MDISA in Columns (3) and (4) are, respectively, 1.647 and 0.129, which mean that carbon dioxide emissions have a significantly positive impact on man-made disasters. The mediating effect is 0.053 , and the Sobel test is 2.336 , and the mediating effect is also significant. Moreover, man-made disasters can mediate the effect of climate change on the non-performing loan ratio. The coefficient of TEMP in Column (5) is 0.250 and insignificant. However, man-made disasters have 
Table 9 Estimation result of $B L L P$ : mediating effect

\begin{tabular}{|c|c|c|c|c|c|c|}
\hline & Mediating variable: $D I S A$ & & & & & \\
\hline \multirow[t]{2}{*}{ Dependent Variable } & (1) & (2) & (3) & (4) & (5) & (6) \\
\hline & DISA & $B L L P$ & DISA & $B L L P$ & DISA & $B L L P$ \\
\hline$D I S A$ & & $\begin{array}{l}0.439 \\
(1.343)\end{array}$ & & $\begin{array}{l}9.774 * \\
(1.673)\end{array}$ & & $\begin{array}{l}0.029^{* *} \\
(2.510)\end{array}$ \\
\hline FOR & $\begin{array}{l}-459.844 \\
(-0.491)\end{array}$ & & & & & \\
\hline$C A R B$ & & & $\begin{array}{l}0.262 * * * \\
(9.122)\end{array}$ & & & \\
\hline TEMP & & & & & $\begin{array}{l}45.843 * * * \\
(3.002)\end{array}$ & \\
\hline Mediating effect & -201.872 & $2.561 *$ & $1.329 *$ & & & \\
\hline Sobel test & $\begin{array}{l}-0.471 \\
\text { Mediating variable: } M D I S A\end{array}$ & 1.646 & 1.926 & & & \\
\hline Dependent Variable & (1) & (2) & (3) & (4) & (5) & (6) \\
\hline & $M D I S A$ & $B L L P$ & MDISA & $B L L P$ & MDISA & $B L L P$ \\
\hline$M D I S A$ & & $\begin{array}{l}2.531 * * \\
(2.194)\end{array}$ & & $\begin{array}{l}0.397 * * \\
(2.332)\end{array}$ & & $\begin{array}{l}14.951^{* *} \\
(2.045)\end{array}$ \\
\hline FOR & $\begin{array}{l}-15.410^{* * *} \\
(-3.668)\end{array}$ & & & & & \\
\hline$C A R B$ & & & $\begin{array}{l}1.125 * * * \\
(16.233)\end{array}$ & & & \\
\hline TEMP & & & & & $\begin{array}{l}0.295^{*} \\
(1.834)\end{array}$ & \\
\hline Mediating effect & $-39.002 *$ & $0.447 * *$ & 4.411 & & & \\
\hline Sobel test & -1.883 & 2.308 & 1.365 & & & \\
\hline
\end{tabular}

Same as Table 4

a significantly positive effect on the non-performing loan ratio. Hence, the indirect effect of temperature change is 1.133 and also insignificant, which means that influences of temperature on man-made disasters and man-made disasters on the nonperforming loan ratio are both positive. We find that an increase of 1 unit of FOR will decrease 53.503 units of the non-performing loan ratio, and an increase of 1 unit of $C A R B$ rise 0.053 units of $B A D L$, and an increase of 1 unit of TEMP will rise 1.133 units of the non-performing loan ratio through man-made disasters. It is obvious that the mediating effect of temperature change on the non-performing loan ratio is insignificant, while the mediating effects of forest land and carbon dioxide emissions are both significant.

Second, Table 7 also reveals the estimation result of the mediating impact of climate change on the ratio of capital to assets through man-made disasters. We find that climate change has a strong mediating effect on ASSR. The coefficients of FOR and MDISA in Columns (1) and (2) are, respectively, -13.150 and -0.099 and both 
significant at the $1 \%$ level, which means that the mediating effect is 1.302 , and the Sobel test is 1.642. It indicates that more forest land decreases man-made disasters and thus helps to reduce the ratio of capital to assets of a bank. Moreover, carbon dioxide emissions have a positive impact on man-made disasters, and the coefficient of MDISA in Column (4) is -0.071 , which indicates that the mediating effect is -0.077 , and the Sobel test is -2.044 , and the mediating effect is also significant. We conclude that carbon dioxide emissions can decrease ASSR through greater man-made disasters. Furthermore, the influence of temperature change on the economic losses of man-made disasters is 0.272 or insignificant. However, MDISA has a strongly negative effect on $A S S R$. It indicates that the ratio of capital to assets will increase by 1.302 units, -0.077 units, and -0.075 units along with an increase of 1 unit in the ratio of forest land to national area, the ratio of carbon dioxide emissions to national area, and temperature change via the mediating effect of man-made disasters. We conclude that there only exist significant mediating impacts of forest land and carbon dioxide emissions on the ratio of capital to assets of banks through manmade disasters.

Why does climate change affect bank performance through man-made disasters? First, it is obvious that heavy rain, snowstorms, and strong winds may cause industrial fires and even transport accidents. Smog and duststorms are bad for the sight of drivers of motor vehicles and thus can cause traffic accidents. Strong winds and waves increase the mistakes of pilots of ships, potentially leading to oil spills and gas leaks. Moreover, high temperature is also bad for the operations of some parts of production and motor vehicles, which could result in explosions or fires. Second, the assets of enterprises and residents that suffer from man-made disasters may incur losses. Enterprises of course do not benefit from equipment losses and might be unable to repay bank debts. The impact of man-made disasters on residents is also serious, including threats to their health or lives, and they may also be unable to repay loans. Therefore, non-performing loans of banks increase. Finally, if banks cannot recover loans from enterprises and residents suffering from man-made disasters, then their ratio of capital to assets may decline, which is similar to the analysis of natural disasters. Climate change increases the costs of man-made disasters, which have negative effects on bank performance.

(2) The change of the dependent variable.

This paper initially uses DISAD and MDISAD to verify the mediating effect of climate change on banks' non-performing loan ratio. First, Table 8 displays a similar conclusion to that of DISA as the dependent variable. Columns (1) and (2) show that the coefficients of FOR and DISAD are -1.935 and 29.815, respectively, and significant at the $10 \%$ level. The mediating effect is -57.692 and also significant. The effects of $C A R B$ on DISAD and DISAD on BADL are, respectively, 0.003 and 66.476. Although the indirect impact is 0.199 and insignificant, it is still positive. The coefficients of TEMP on DISAD are, respectively, 0.106 and 18.206 and are significant. The mediating effect and Sobel test are, respectively, 1.929 and 1.766, revealing that there exists a mediating effect of temperature change on banks' non-performing loan ratio. The above conclusions indicate that forest land and temperature change both affect bank performance through deaths due to natural disasters, except for carbon dioxide emissions. However, they have the same sign as in Table 4. Table 8 also 
Table 10 Estimation result of $B A D L$ via changing the method

\begin{tabular}{|c|c|c|c|c|c|c|}
\hline Independent Variable & (1) & (2) & (3) & (4) & (5) & (6) \\
\hline DISA & DISA & $\begin{array}{l}B A D L \\
0.014 * * * \\
(3.056)\end{array}$ & $D I S A$ & $\begin{array}{l}B A D L \\
0.607 \\
(1.285)\end{array}$ & DISA & $\begin{array}{l}B A D L \\
0.056^{* * * *} \\
(3.222)\end{array}$ \\
\hline FOR & $\begin{array}{l}-1.935 * * * \\
(-2.949)\end{array}$ & & & & & \\
\hline$C A R B$ & & & $\begin{array}{l}0.003 \\
(0.286)\end{array}$ & & & \\
\hline TEMP & & & & & $\begin{array}{l}2.106^{* *} \\
(2.270)\end{array}$ & \\
\hline PEON & $\begin{array}{l}-0.012 \\
(-0.037)\end{array}$ & $\begin{array}{l}-6.606^{* *} \\
(-2.078)\end{array}$ & $\begin{array}{l}0.256 \\
(0.302)\end{array}$ & $\begin{array}{l}-7.550 * * \\
(-2.002)\end{array}$ & $\begin{array}{l}0.091 \\
(0.109)\end{array}$ & $\begin{array}{l}-8.319 \\
(-1.099)\end{array}$ \\
\hline$G D P$ & $\begin{array}{l}-0.014 \\
(-1.166)\end{array}$ & $\begin{array}{l}-0.898 * * * \\
(-8.084)\end{array}$ & $\begin{array}{l}-0.006 \\
(-0.704)\end{array}$ & $\begin{array}{l}0.812 * * * \\
(-6.347)\end{array}$ & $\begin{array}{l}0.008 \\
(0.630)\end{array}$ & $\begin{array}{l}-0.987 * * * \\
(-8.466)\end{array}$ \\
\hline TRADE & & $\begin{array}{l}0.012 * * * \\
(2.987)\end{array}$ & & $\begin{array}{l}0.012 * * * \\
(2.631)\end{array}$ & & $\begin{array}{l}0.017 * * * \\
(3.888)\end{array}$ \\
\hline$I N F L$ & & $\begin{array}{l}-0.038 \\
(-1.269)\end{array}$ & & $\begin{array}{l}-0.038 \\
(-1.108)\end{array}$ & & $\begin{array}{l}-0.032 \\
(-0.994)\end{array}$ \\
\hline RATE & & $\begin{array}{l}-0.051^{*} \\
(-1.842)\end{array}$ & & $\begin{array}{l}-0.009 \\
(-0.282)\end{array}$ & & $\begin{array}{l}-0.077 * * \\
(-2.557)\end{array}$ \\
\hline Constant & $\begin{array}{l}0.124 * * * \\
(2.650)\end{array}$ & $\begin{array}{l}7.445^{* * * *} \\
(14.654)\end{array}$ & $\begin{array}{l}0.028 \\
(1.323)\end{array}$ & $\begin{array}{l}6.772 * * * \\
(11.222)\end{array}$ & $\begin{array}{l}-0.173 * * * \\
(-3.112)\end{array}$ & $\begin{array}{l}7.352 * * * \\
(13.612)\end{array}$ \\
\hline Mediating effect & $-0.027 * *$ & 0.002 & $0.118^{*}$ & & & \\
\hline Sobel test & -2.122 & 0.279 & 1.856 & & & \\
\hline Obs & 1216 & 1216 & 859 & 859 & 1140 & 1140 \\
\hline$R 2$ & 0.456 & 0.317 & 0.333 & 0.391 & 0.417 & 0.425 \\
\hline F test & 5.087 & 6.158 & 6.779 & 7.198 & 5.433 & 6.232 \\
\hline
\end{tabular}

Here, we use the stepwise regression by considering the panel fixed effect model. The parameters are the same as Table $4 .{ }^{* * *},{ }^{* *}$, and ${ }^{*}$ indicate statistical significance at the $1 \%, 5 \%$, and $10 \%$ levels, respectively

reveals a similar result to that of MDISA as the dependent variable. The coefficients of FOR and MDISAD in Columns (1) and (2) are, respectively, -49.767 and 1.429, both significant at the $1 \%$ level, which indicate that the mediating effect is -71.117 , and the Sobel test is -2.564. It reveals that forest land can reduce deaths from manmade disasters, and so MDISAD has a positive impact on the non-performing loan ratio. The effects of $C A R B$ on MDISAD and MDISAD on BADL are, respectively, 8.184 and 0.112 , or both significant at the $5 \%$ level, which mean that the indirect impact is 0.917 and also significant. The coefficients of TEMP and MDISAD in Columns (5) and (6) are, respectively, 0.404 and 8.911. Although the mediating effect is 3.600 and insignificant, it is still positive. Therefore, the original dependent variable is effective.

(3) The change of the independent variable. 
Table 9 presents the ratio of loan loss provisions to bank assets $(B L L P)$ to measure bank loss. The data of BLLP come from the BankFocus database. First, the coefficients of FOR and DISA in Columns (1) and (2) are, respectively, -459.844 and 0.439 , which are both insignificant. Hence, the mediating effect is -201.872 and also insignificant. Carbon dioxide emissions have significantly positive influences on natural disasters, and DISA affects BLLP positively and significantly. In addition, the mediating effect is 2.561 , and the Sobel test is 1.646 . It indicates that carbon dioxide emissions increase natural disasters, which result in damage to enterprises and residents, and the ratio of loan loss provisions to total assets rises, because banks cannot recall loans. The effects of TEMP on DISAD and DISAD on BLLP are, respectively, 45.843 and 0.029 , or both significant at the $5 \%$ level, meaning that the indirect impact is 1.329 and also significant. Furthermore, the mediating effect of manmade disasters exists. The coefficients of FOR and DISA in Columns (1) and (2) are, respectively, -15.410 and 2.531 , and both are significant. Moreover, the mediating impact is -39.002 , and the Sobel test is -1.883 . The result shows that forest land decreases man-made disasters, which increase BLLP. Carbon dioxide emissions have a strongly positive influence on MDISA, which also affects $B L L P$ positively. Although the effects of TEMP on MDISAD and MDISAD on BLLD are, respectively, 0.295 and 14.951 , or both significant at the $10 \%$ level, and so the mediating effect is insignificant. However, the mediating effect of temperature change is positive.

We conclude that climate change still raises the number of natural and manmade disasters, which then lead to damage to the lives of residents and enterprises", production. In addition, banks need to increase loan loss provisions to prevent the increase of non-performance loans and to ensure normal operations of banks.

(4) The change of the method.

Table 10 uses the stepwise regression with regard to fixed panel estimation to verify the mediating effect. Columns (1) and (2) also obtain similar results in that the coefficients of FOR and DISAD are significant at -1.935 and 0.014 . The mediator of the economic losses of natural disasters is -0.027 and significant at the $5 \%$ level, showing that natural disasters mediate the effect of forest land on banks' nonperforming loan ratio. From Columns (3) and (4), we get the same conclusion that the parameters of $C A R B$ and DISAD are both insignificant, but positive, at 0.003 and 0.607. The indirect effect is 0.002 , and the Sobel test is 0.279 , both of which are positive and the same as with the above analysis. Finally, temperature change has a positive and significant influence on natural disasters at 2.106. In addition, the coefficient of DISAD in Column (6) is 0.056, showing that the mediating effect is 0.118 and significant at the $10 \%$ level. In short, this paper gets similar results by using the method of stepwise regression, and the original method is valid.

\section{Conclusion and policy implication}

Based on unbalanced panel data of 127 countries in the world during 2005-2018, we use the three-stage least square method and mediating effect model for parameter estimation to study the indirect effect of climate change on bank performance 
through the economic losses of natural disasters. The main conclusions are as follows. First, forest land has a strong negative effect on the non-performing loan ratio and an insignificantly negative impact on the ratio of capital to assets. Carbon dioxide emissions and temperature change also have significantly positive effects on the non-performing loan ratio, but negative influences on the ratio of capital to assets. Second, forest land decreases the economic losses and deaths due to natural disasters, which also decrease banks' non-performing loan ratio. However, carbon dioxide emissions and temperature change increase the economic losses and deaths from natural disasters, which raise banks' non-performing loan ratio. We also find that forest land increases the ratio of bank capital to assets through decreasing natural disasters, and carbon dioxide emissions and temperature change decrease the ratio of bank capital to assets via increasing natural disasters. Finally, the mediating effect is significant in high-income countries and insignificant in low-income countries.

The conclusions of our paper can be helpful to improve climate change, prevent natural disasters, and promote financial institutions. The key to maintaining the normal operations of banks is to decrease $\mathrm{CO} 2$ emissions, increase forest land, strengthen infrastructure, improve the income and livelihood of humans, and develop industry ecologically. Thus, the policy implications of this study's conclusion are the following three aspects.

(1) How to improve climate change? First, governments should increase forest land and grassland. Developing countries should improve science and technology and do not cut down trees and grasslands to develop the economy. Moreover, a government should punish those deforestations by constructing a strong regulatory system. Second, it is reasonable to develop cities ecologically. The government must increase revenue to increase the coverage of green plants per unit of urban area. It is also important to raise the use of clean energy vehicles and reduce the use of motor vehicles. The industry also needs to improve its technology and innovation and accumulate pollution treatment technology at home or abroad, which can help reasonably utilize waste during production and minimize pollution to the environment. Finally, global climate change has become more serious currently, and countries need to increase research funds for reducing its current level, especially for greenhouse gases in the atmosphere. There is an urgent need to strengthen cooperation among countries to improve human life through environmental protection.

(2) How to prevent natural disasters? It takes much time to turn around climate change. Hence, the main goal at this stage is to develop technologies to improve it and prevent natural disasters caused by it. First, it is necessary to establish reasonable dam structures for those regions prone to floods and improve the mobilization mechanism of the affected population so as to minimize deaths and economic losses. Second, the government needs to improve the quality of buildings and plant more trees to prevent economic losses caused by tsunamis and storms in coastal areas. In addition, it is necessary to establish monitoring equipment on the coast and at sea that can detect natural disasters as soon as possible. Finally, poor developing countries have a weak ability to deal with natural disasters. Other countries, especially developed ones, should supply technology and equipment to these poor developing 
countries to help prevent natural disasters and provide humanitarian assistance to countries that have already suffered from natural disasters.

(3) How to promote the performance of financial institutions? The development of financial institutions in low-income countries is backward and cannot accumulate sufficient and effective deposits in order to create loans and investment for individuals and enterprises. Hence, other developed countries should provide technical support and offer their experience to financial institutions of low-income countries. Second, the government needs to establish financial supervision institutions and a solid credit reporting system to prevent corruption, non-performing loans, etc. Finally, financial institutions also should set reasonable interest rates for deposits and loans, so that residents and enterprises are willing to make deposits and request loans. Furthermore, banks must use the assets from residents and enterprises to invest in other enterprises and projects in order to ensure the valid use of funds.

\section{Declarations}

Conflict of interest The authors declare that they have no competing financial interests or personal relationships that could have appeared to influence the work reported in this paper.

\section{References}

Adebisi JF, Matthew OB (2015) The impact of non-performing loans on firm profitability: a focus on the Nigerian banking industry. Am Res J Bus Manag 1(4):1-7

Albuquerque PH, Rajhi W (2019) Banking stability, natural disasters, and state fragility: panel VAR evidence from developing countries. Res Int Bus Financ 50:430-443

Amin AS, Imam MO, Malik M (2019) Regulations, governance, and resolution of non-performing loan: evidence from an emerging economy. Emerg Mark Financ Trade 55(10):2275-2297

Ardhuin F, Gille ST, Menemenlis D, Rocha CB, Rascle N, Chapron B, Molemaker J (2017) Smallscale open ocean currents have large effects on wind wave heights. J Geophys Res Oceans 122(6):4500-4517

Barrimah I, Midhet F, Sharaf F (2012) Epidemiology of road traffic injuries in Qassim region, Saudi Arabia: consistency of police and health data. Int J Health Sci 6(1):31

Baryshnikova NV, Pham NT (2019) Natural disasters and mental health: a quantile approach. Econ Lett 180:62-66

Belingardi G, Chiandussi G, Gobetto E et al (2010) Bonnet weight reduction and VRU protection: design proposals implementing non-conventional materials. Int $\mathrm{J}$ Automot Technol 11(6):831-842

Boateng A, Huang W, Kufuor NK (2015) Commercial bank ownership and performance in China. Appl Econ 47(49):5320-5336

Brahmana R, Puah C, Chai M (2016) Natural disaster and local bank non-performing loan: case of Nias tsunami 2004. Economics Bulletin 36(4):2413-2421

Brei M, Mohan P, Strobl E (2019) The impact of natural disasters on the banking sector: evidence from hurricane strikes in the Caribbean. Q Rev Econ Finance 72:232-239

Brueckner M, Lederman D (2015) Trade openness and economic growth: panel data evidence from SubSaharan Africa. Economica 82:1302-1323

Cao W, Wang H, Ying H (2017) The effect of environmental regulation on employment in resource-based areas of China- an empirical research based on the mediating effect model. Int J Environ Res Public Health 14(12):1598

Chang CP, Berdiev AN (2013) Natural disasters, political risk and insurance market development. Geneva Papers Risk Insurance-Issues Practice 38(3):406-448 
Chang CP, Berdiev AN (2015) Do natural disasters increase the likelihood that a government is replaced? Appl Econ 47(17):1788-1808

Chang CP, Feng GF, Zheng M (2021) Government Fighting Pandemic Stock Market Return and COVID19 Virus Outbreak. Emerging Markets Finance and Trade 57(8):2389-2406. https://doi.org/10. 1080/1540496X.2021.1873129

Chang CP, Zhang LW (2020) Do natural disasters increase financial risks? An empirical analysis. Buletin Ekonomi Moneter Dan Perbankan 23:61-86

Chen YE, Li C, Chang CP et al (2021) Identifying the influence of natural disasters on technological innovation. Econom Anal Policy 70(7):22-36

Cheng X, Yang B, Liu G et al (2018) A total bounded variation approach to low visibility estimation on expressways. Sensors 18(2):392

Chen YE, Fu Q, Zhao X, Yuan X, Chang CP (2019) International sanctions' impact on energy efficiency in target states. Economic Modelling 82:21-34. https://doi.org/10.1016/j.econmod.2019.07.022

Clough SA, Iacono MJ (1995) Line-by-line calculation of atmospheric fluxes and cooling rates: 2. Application to carbon dioxide, ozone, methane, nitrous oxide and the halocarbons. J Geophys Res Atmospheres 100(8):16519-16535

Cole MA, Elliott RJ, Okubo T, Strobl E (2019) Natural disasters and spatial heterogeneity in damages: the birth, life and death of manufacturing plants. J Econom Geography 19(2):373-408

Cortés KR, Strahan PE (2017) Tracing out capital flows: How financially integrated banks respond to natural disasters. J Financ Econ 125(1):182-199

Cox PM, Pearson D, Booth BB, Friedlingstein P, Huntingford C, Jones CD, Luke CM (2013) Sensitivity of tropical carbon to climate change constrained by carbon dioxide variability. Nature 494(7437):341-344

Dalmagro HJ, Zanella de Arruda PH, Vourlitis GL, Lathuillière MJ, de Nogueira SJ, Couto EG, Johnson MS (2019) Radiative forcing of methane fluxes offsets net carbon dioxide uptake for a tropical flooded forest. Global Change Biol 25(6):1967-1981

Diaz JH (2006) Global climate changes, natural disasters, and travel health risks. J Travel Med 13(6):361-372

Dong K, Sun R, Li H, Liao H (2018) Does natural gas consumption mitigate CO2 emissions: testing the environmental Kuznets curve hypothesis for 14 Asia-Pacific countries. Renew Sustain Energy Rev 94:419-429

Feng W, Liu Y, Qu L (2019) Effect of land-centered urbanization on rural development: a regional analysis in China. Land Use Policy 87:104072

Feng GF, Wang QJ, Chu Y et al (2021a) Does the shale gas boom change the natural gas price-production relationship? Evidence from the US market. Energy Economics 93(1):104327

Feng GF, Yang Qiang HC, Gong Q, Chang CP (2021b) What is the exchange rate volatility response to COVID-19 and government interventions?. Econ Anal Policy 69:705-719. https://doi.org/10. 1016/j.eap.2021.01.018

Fernandes A, Rollinson CR, Kearney WS, Dietze MC, Fagherazzi S (2018) Declining radial growth response of coastal forests to hurricanes and nor'easters. J Geophys Res Biogeosci 123(3):832-849

Fu Q, Chen YE, Jang CL, Chang CP (2020) The impact of international sanctions on environmental performance. Science of The Total Environment 745:141007. https://doi.org/10.1016/j.scitotenv. 2020.141007.

García-Sánchez IM, Gómez-Miranda ME, David F, Rodríguez-Ariza L (2019) Board independence and GRI-IFC performance standards: the mediating effect of the CSR committee. J Clean Prod 225:554-562

Ghosh A (2016) Banking sector globalization and bank performance: a comparative analysis of low income countries with emerging markets and advanced economies. Rev Dev Finance 6(1):58-70

Gilchrist S, Schoenle R, Sim J, Zakrajšek E (2017) Inflation dynamics during the financial crisis. Am Econom Rev 107(3):785-823

Guerreiro SB, Dawson RJ, Kilsby C, Lewis E, Ford A (2018) Future heat-waves, droughts and floods in 571 European cities. Environ Res Letts 13(3):034009

Harmooshi NN, Shirbandi K, \& Rahim F (2020) Environmental concern regarding the effect of humidity and temperature on 2019-nCoV survival: fact or fiction. Environmental Science and Pollution Research, 1-10

Harrington LJ, Otto FE (2020) Reconciling theory with the reality of African heatwaves. Nat Clim Chang 10(9):796-798 
Hassan RM (2010) Implications of climate change for agricultural sector performance in Africa: Policy challenges and research agenda. J Afr Econom 19(suppl_2):ii77-ii105

Herold N, Alexander L, Green D, Donat M (2017) Greater increases in temperature extremes in low versus high income countries. Environ Res Letts 12(3):034007

Hirsch RM, Ryberg KR (2012) Has the magnitude of floods across the USA changed with global CO2 levels? Hydrol Sci J 57(1):1-9

Hong Y (2017) A study on the condition of temporary housing following disasters: Focus on container housing. Front Arch Res 6(3):374-383

Huang L, Pei S, Wang Y et al (2019) Assessment of flammability and explosion risks of natural gasair mixtures at high pressure and high temperature. Fuel 247:47-56

Islam M, Alharthi M, Alam M (2019) The impacts of climate change on road traffic accidents in Saudi Arabia. Climate 7(9):103

Jiménez G, Lopez JA, Saurina J (2013) How does competition affect bank risk-taking? J Financ Stab 9(2):185-195

Keerthiratne S, Tol RS (2018) Impact of natural disasters on income inequality in Sri Lanka. World Dev 105:217-230

Kellenberg DK, Mobarak AM (2008) Does rising income increase or decrease damage risk from natural disasters? J Urban Econ 63(3):788-802

Kenisarin MM (2010) High-temperature phase change materials for thermal energy storage. Renew Sustain Energy Rev 14(3):955-970

Khan MMH, Bryceson I, Kolivras KN, Faruque F, Rahman MM, Haque U (2015) Natural disasters and land-use/land-cover change in the southwest coastal areas of Bangladesh. Reg Environ Change 15(2):241-250

Klomp J (2014) Financial fragility and natural disasters: an empirical analysis. J Financ Stab 13:180-192

Knowles N, Dettinger MD, Cayan DR (2006) Trends in snowfall versus rainfall in the western United States. J Clim 19(18):4545-4559

Konishi M, Yasuda Y (2004) Factors affecting bank risk taking: evidence from Japan. J Bank Finance 28(1):215-232

Koyanagi A, Stubbs B, Oh H, Veronese N, Smith L, Haro JM, Vancampfort D (2019) Food insecurity (hunger) and suicide attempts among 179,771 adolescents attending school from 9 high-income, 31 middle-income, and 4 low-income countries: a cross-sectional study. J Affect Disord 248:91-98

Labovská Z, Labovský J, Jelemenský L' et al (2014) Model-based hazard identification in multiphase chemical reactors. J Loss Prev Process Ind 29:155-162

Long H, Chang CP, Jegajeevan S, Tang K (2021) Can central bank mitigate the effects of the COVID-19 pandemic on the macroeconomy?. Emerg Markets Finance Trade (forthcoming)

Lashof DA, Ahuja DR (1990) Relative contributions of greenhouse gas emissions to global warming. Nature 344(6266):529-531

Lee M, Hong JH, Kim KY (2017) Estimating damage costs from natural disasters in Korea. Nat Hazard Rev 18(4):04017016

Lee WK, Lee HA, Hwang S et al. (2015) Does temperature modify the effects of rain and snow precipitation on road traffic injuries?. J Epidemiol, JE20140244

Levy K, Woster AP, Goldstein RS, Carlton EJ (2016) Untangling the impacts of climate change on waterborne diseases: a systematic review of relationships between diarrheal diseases and temperature, rainfall, flooding, and drought. Environ Sci Technol 50(10):4905-4922

Li Z, Liu D, Yan W et al (2019) Dense fog burst reinforcement over Eastern China: a review. Atmospheric Res 230:104639

Lima RCDA, Barbosa AVB (2019) Natural disasters, economic growth and spatial spillovers: evidence from a flash flood in Brazil. Pap Reg Sci 98(2):905-924

Liu W, Wu J, Tang R, Ye M, Yang J (2020) Daily Precipitation threshold for rainstorm and flood disaster in the mainland of China: an economic loss perspective. Sustainability 12(1):407

Loayza NV, Olaberria E, Rigolini J, Christiaensen L (2012) Natural disasters and growth: going beyond the averages. World Dev 40(7):1317-1336

Lopez JA, Rose AK, Spiegel MM (2020) Why have negative nominal interest rates had such a small effect on bank performance? Cross country evidence. Euro Econom Rev 124:103402

Lu H, Chen M, Kuang W (2020) The impacts of abnormal weather and natural disasters on transport and strategies for enhancing ability for disaster prevention and mitigation. Transp Policy 98:2-9 
Marin G, Modica M (2017) Socio-economic exposure to natural disasters. Environ Impact Assess Rev 64:57-66

Miao Q, Eva N, Newman A, Cooper B (2019) Ceo entrepreneurial leadership and performance outcomes of top management teams in entrepreneurial ventures: the mediating effects of psychological safety. J Small Bus Manage 57(3):1119-1135

Modarres R, Sarhadi A, Burn DH (2016) Changes of extreme drought and flood events in Iran. Global Planet Change 144:67-81

Montzka SA, Dlugokencky EJ, Butler JH (2011) Non-CO 2 greenhouse gases and climate change. Nature 476(7358):43-50

Mourouzidou-Damtsa S, Milidonis A, Stathopoulos K (2019) National culture and bank risk-taking. J Financ Stab 40:132-143

Narayan PK (2003) Macroeconomic impact of natural disasters on a small island economy: evidence from a CGE model. Appl Econ Lett 10(11):721-723

Nezamodini ZS, Rezvani Z, Kian K (2015) Fire and explosion risk assessment in a process unit using Dow's Fire and Explosion Index. Health Safety Work 4(4):29-38

Noth F, \& Schüwer U (2018) Natural disaster and bank stability: evidence from the US financial system. Annual Conference 2017 (Vienna): Alternative Structures for Money and Banking Verein für Socialpolitik/German Economic Association, 2017

Noy I (2009) The macroeconomic consequences of disasters. J Dev Econ 88(2):221-231

Okubo R, Inoue T, Hashimoto $\mathrm{N}$ et al (2017) The mediator effect of personality traits on the relationship between childhood abuse and depressive symptoms in schizophrenia. Psychiatry Res 257:126-131

Panagiotis G, \& Victoria B (2016) The relationship between leader self-deprecating humor and perceived effectiveness: trust in leader as a mediator. Leadership Organ Dev J, 37(7)

Pennacchi G (2006) Deposit insurance, bank regulation, and financial system risks. J Monet Econ 53(1):1-30

Samantha G (2018) The impact of natural disasters on micro, small and medium enterprises (MSMEs): a case study on 2016 flood event in Western Sri Lanka. Procedia Engineering 212:744-751

Sant'Anna AA (2018) Not so natural: Unequal effects of public policies on the occurrence of disasters. Ecol Econom 152:273-281

Shirai S, Sugandi EA (2019) Growing global demand for cash. Int Bus Res 12(12):74-92

Sommer JM (2019) Ecologically unequal exchange and national governance: a cross-national analysis of forest loss. Environ Policy Gov 29(6):422-434

Song CQ, Chang CP, Gong Q (2021) Economic growth, corruption, and financial development: global evidence. Econ Model 94:822-830

Thiagarajan S (2018) An analysis of performance of commercial banks in Belize during post global recession period. J Finance Bank Manag 6(2):33-47

Tofighi D, MacKinnon DP (2011) RMediation: an R package for mediation analysis confidence intervals. Behav Res Methods 43(3):692-700

Ullah A, Salehnia N, Kolsoumi S, Ahmad A, Khaliq T (2018) Prediction of effective climate change indicators using statistical downscaling approach and impact assessment on pearl millet (Pennisetum glaucum L.) yield through Genetic Algorithm in Punjab. Pakistan Ecol Indicators 90:569-576

Us V (2017) Dynamics of non-performing loans in the Turkish banking sector by an ownership breakdown: the impact of the global crisis. Financ Res Lett 20:109-117

Van-Aalst MK (2006) The impacts of climate change on the risk of natural disasters. Disasters 30(1):5-18

Wang L, Xiong X (2021) The impact of herding behaviour of Chinese securities investment funds on firm value: the mediating effects of stock price informativeness and agency cost. Applied Economics Letters 5:1-8 (Online)

Wang QT, Feng G-F, Wang H-J, Chang C-P (2021a) The impacts of democracy on innovation: Revisited evidence. Technovation 108:102333. https://doi.org/10.1016/j.technovation.2021.102333

Wang H, An K, Zheng M (2021b) Who has done a better job in fighting the COVID-19 epidemic? Left or Right?. Emerg Markets Finance Trade 57(8):2415-2425. https://doi.org/10.1080/1540496X.2021. 1908259

Wang Y, Taylor JE (2018) Coupling sentiment and human mobility in natural disasters: a Twitter-based study of the 2014 South Napa Earthquake. Nat Hazards 92(2):907-925

Wei W, Zhang WL, Wen J, Wang JS (2020) TFP growth in Chinese cities: The role of factor-intensity and industrial agglomeration. Econ Model 91:534-549

Wen J, Chang CP (2015) Government ideology and the natural disasters: a global investigation. Nat Hazards 78(3):1481-1490 
Wen J, Zhao X, Wang Q-J, Chang C-P (2021) The impact of extreme events on energy price risk. Energy Economics 99, 105308. https://doi.org/10.1016/j.eneco.2021.105308

Wen J, Zhao X, Wang Q-J, Chang C-P (2020) The impact of international sanctions on energy security. Energy \& Environment 32(3):458-480. https://doi.org/10.1177/0958305X20937686

Williams J (2013) Exploring the onset of high-impact mega-fires through a forest land management prism. For Ecol Manage 294:4-10

Xi W, Chen SHV, Chu YC (2012) The synergistic effects of typhoon and earthquake disturbances on forest ecosystems: lessons from Taiwan for ecological restoration and sustainable management. Forest 391(18.61):99-401

Yang H, Dietz T, Yang W, Zhang J, Liu J (2018) Changes in human well-being and rural livelihoods under natural disasters. Ecol Econ 151:184-194

Yang Y, Zheng H, Xu W et al (2019) Temporal changes in multiple ecosystem services and their bundles responding to urbanization and ecological restoration in the Beijing-Tianjin-Hebei Metropolitan Are. Sustainability 11(7):2079

Yang HC, Syarifuddin F, Chang CP, Wang HJ (2021) The impact of exchange rate futures fluctuations on macroeconomy: evidence from ten trading market. Emerg Markets Finance Trade. https://doi.org/ 10.1080/1540496X.2021.1976636

Zhao Y, Lee JP, Yu MT (2021) Catastrophe risk, reinsurance and securitized risk-transfer solutions: a review. China Finance Rev Int 8:1-26 (Online)

Zheng W, Zhou YL, Liu WJ, Wang CY, Zhan YN, Li HQ, Ning YP (2019) Neurocognitive performance and repeated-dose intravenous ketamine in major depressive disorder. J Affect Disord 246:241-247

Zheng M, Feng GF, Jang CL, Chang CP (2021) Terrorism and green innovation in renewable energy. Energy Economics 104:105695. https://doi.org/10.1016/j.eneco.2021.105695

Zickfeld K, MacDougall AH, Matthews HD (2016) On the proportionality between global temperature change and cumulative $\mathrm{CO} 2$ emissions during periods of net negative $\mathrm{CO} 2$ emissions. Environ Res Letts 11(5):055006

Zoback MD, Gorelick SM (2012) Earthquake triggering and large-scale geologic storage of carbon dioxide. Proc Natl Acad Sci 109(26):10164-10168

Publisher's Note Springer Nature remains neutral with regard to jurisdictional claims in published maps and institutional affiliations. 